UNIVERSIDADE TECNOLÓGICA FEDERAL DO PARANÁ

PROGRAMA DE PÓS-GRADUAÇÃO EM SISTEMAS DE ENERGIA

ANA LÚCIA VIEIRA IAREMCZUK

OTIMIZAÇÃO DO CONSUMO ENERGÉTICO EM SISTEMAS DE CONTROLE SEM FIO ATRAVÉS DE CONTROLE PREDITIVO E REDUNDÂNCIA INCREMENTAL

DISSERTAÇÃO

CURITIBA 
OTIMIZAÇÃO DO CONSUMO ENERGÉTICO EM SISTEMAS DE CONTROLE SEM FIO ATRAVÉS DE CONTROLE PREDITIVO E REDUNDÂNCIA INCREMENTAL

\section{OPTIMIZATION OF ENERGY CONSUMPTION IN WIRELESS CONTROL SYSTEMS THROUGH PREDICTIVE CONTROL AND INCREMENTAL REDUNDANCY}

Dissertação apresentada ao Programa de Pósgraduação em Sistemas de Energia da Universidade Tecnológica Federal do Paraná como requisito parcial para obtenção do título de "Mestre em Engenharia Elétrica" - Área de Concentração: Automação e Sistemas de Energia.

Orientador: Prof. Dr. Guilherme Luiz Moritz

CURITIBA

2020 
Ministério da Educação

Universidade Tecnológica Federal do Paraná

Câmpus Curitiba

\title{
OTIMIZAÇÃO DO CONSUMO ENERGÉTICO EM SISTEMAS DE CONTROLE SEM FIO ATRAVÉS DE CONTROLE PREDITIVO E REDUNDÂNCIA INCREMENTAL
}

\author{
Trabalho de pesquisa de mestrado apresentado como \\ requisito para obtenção do título de Mestra Em Engenharia \\ Elétrica da Universidade Tecnológica Federal do Paraná \\ (UTFPR). Área de concentração: Automação E Sistemas De \\ Energia.
}

Data de aprovação: 18 de Dezembro de 2020

Prof Guilherme Luiz Moritz, Doutorado - Universidade Tecnológica Federal do Paraná

Prof Guilherme De Santi Peron, Doutorado - Universidade Tecnológica Federal do Paraná

Prof Richard Demo Souza, Doutorado - Universidade Federal de Santa Catarina (Ufsc)

Documento gerado pelo Sistema Acadêmico da UTFPR a partir dos dados da Ata de Defesa em 18/12/2020. 


\section{AGRADECIMENTOS}

Primeiramente, gostaria de agradecer a toda a minha família pelo suporte, especialmente meus pais, Lucimar e Miguel Iaremczuk, por sempre enxergarem a educação como uma prioridade, e fazerem de tudo ao seu alcance para que eu pudesse ter condições de buscar aquilo que eu almejasse. Além disso, por me darem a confiança necessária para seguir na profissão que eu escolhi, independente de qualquer desafio.

Agradeço ao meu orientador, Professor Guilherme Luiz Moritz, por me aceitar neste programa, por toda a sua dedicação em me guiar e auxiliar durante essa jornada, sua abertura e disponibilidade, e ainda pela compreensão e apoio, que tornaram possível a conclusão deste trabalho sem abrir mão das minhas demais obrigações profissionais. Também ao PPGSE, pela oportunidade de participar deste programa de Mestrado.

Agradeço à Volvo do Brasil por sempre incentivar meu desenvolvimento pessoal e profissional, por viabilizar esta oportunidade ao ser flexível para que eu pudesse cursar as disciplinas, e por confiar em mim e no meu trabalho.

Por fim, agradeço à Universidade Tecnológica Federal do Paraná (UTFPR), que por anos praticamente habitei, onde pude me tornar engenheira, e que, durante toda a minha formação superior, inclusive agora, me concedeu suas instalações e recursos. 
"Um dia, quando olhares para trás, verás que os dias mais belos foram aqueles em que lutaste."

\section{Sigmund Freud}




\section{RESUMO}

IAREMCZUK, Ana Lúcia. OTIMIZAÇÃO DO CONSUMO ENERGÉTICO EM SISTEMAS DE CONTROLE SEM FIO ATRAVÉS DE CONTROLE PREDITIVO E REDUNDÂNCIA INCREMENTAL. 49 f. Dissertação - Programa de Pós-graduação em Sistemas de Energia, Universidade Tecnológica Federal do Paraná. Curitiba, 2020.

Os sistemas de controle via rede sem fio são parte integrante dos novos cenários de utilização considerados para a quinta geração de redes móveis $(5 \mathrm{G})$ que, além de superar as gerações anteriores em taxa de dados e capacidade, tem o objetivo de endereçá-los. Eles estão presentes em aplicações como a comunicação V2X e a Indústria 4.0, por exemplo, que utilizam controle em tempo real, o que implica em rigorosos requisitos de latência e confiabilidade da comunicação. Neste tipo de sistema, a forma mais comum de comunicação entre os dispositivos ocorre através de pacotes curtos, demandando um equacionamento específico para um projeto adequado. Ainda, controle e comunicação não podem ser considerados individualmente, pois existem variáveis que exercem influência sobre ambos concomitantemente. Os benefícios da concepção conjunta para atender aos seus requisitos de URLLC (Ultra-Reliable Low Latency Communication) já foram demonstrados ao se melhorar o consumo e, ao mesmo, aumentar o tráfego de informação tempo através do uso de controle preditivo em pacotes. Este é um fator de suma importância, considerando que no contexto dos sistemas sem fio, é comum que os elementos sejam alimentados por baterias. O consumo é reduzido ainda mais quando HARQ (Hybrid Automatic Repeat reQuest) é aplicado, e uma retransmissão da mensagem é prevista em caso de outage. Neste trabalho, ambas as técnicas serão empregadas, levando em conta a comunicação via pacotes curtos, para a obtenção de um número ótimo de retransmissões e comandos de controle preditivo, buscando uma melhor eficiência energética. Os resultados mostraram que, através de uma escolha adequada destes parâmetros, é possível otimizar o consumo. Ainda, que dependendo das restrições de latência do sistema, o uso de controle preditivo em pacotes pode não ser interessante, sendo o HARQ isoladamente uma melhor alternativa.

Palavras-chave: Sistemas de controle, Redes sem fio, Pacotes curtos. 


\begin{abstract}
IAREMCZUK, Ana Lúcia. OPTIMIZATION OF ENERGY CONSUMPTION IN WIRELESS CONTROL SYSTEMS THROUGH PREDICTIVE CONTROL AND INCREMENTAL REDUNDANCY. 49 f. Dissertação - Programa de Pós-graduação em Sistemas de Energia, Universidade Tecnológica Federal do Paraná. Curitiba, 2020.

Wireless networked control systems are an integral part of the new usage scenarios considered for the fifth generation of mobile networks $(5 \mathrm{G})$ which, in addition to surpassing previous generations in data rate and capacity, aim to address them. They are present in applications such as V2X communication and Industry 4.0, for example, using realtime control, which implies strict latency and reliability requirements for communication. In this type of system, the most common form of communication between devices occurs through short packages, requiring specific mathematical models for an appropriate project. Additionally, control and communication cannot be considered individually, as there are variables that influence both concurrently. The co-design benefits for meeting the URLLC (Ultra-Reliable Low Latency Communication) requirements have already been demonstrated by improving resource utilization while increasing information traffic through the use of PPC (Packetized Predictive Control). This is an extremely important factor, considering that in the context of wireless systems, it is common for the elements to be powered by batteries. The consumption is further reduced when HARQ (Hybrid Automatic Repeat reQuest) is applied, and a retransmission of the message is provided in case of an outage event. In this work, both techniques are applied, whereas supporting short packets communication, to obtain an optimum number of retransmissions and predictive control commands, aiming for better energy efficiency. The results show that by performing an appropriate choice of these parameters, it is possible to optimize consumption. Also, depending on the latency restrictions of the system, the use of PPC may not be interesting, being HARQ alone a better alternative.
\end{abstract}

Keywords: Control systems, Wireless networks, Short packets. 


\section{LISTA DE FIGURAS}

Figura 1 - Modelo do sistema de controle, em que o controlador e o atuador se

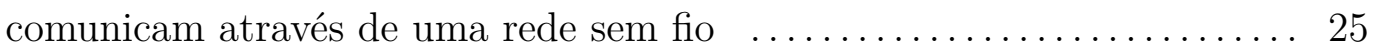

Figura 2 - Estrutura do pacote contendo a sequência de comandos de controle ... 26

Figura 3 - Método para otimização do uso de recursos, empregando redundância

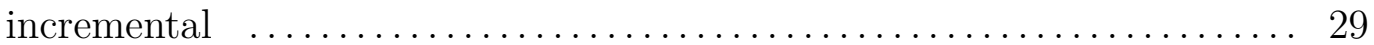

Figura 4 - Consumo em função de $K$ para diferentes valores de $Z$, com $n_{\max }=250 \quad 34$

Figura 5 - Consumo em função de $K$ para diferentes valores de $Z$, com $n_{\max }=350 \quad 34$

Figura 6 - Consumo em função de $K$ para diferentes valores de $Z$, com $n_{\max }=500 \quad 35$

Figura 7 - Contribuição de $E_{1}$ para o total $E_{\text {ir }}$ quando $n_{\max }=250 \ldots \ldots \ldots \ldots$

Figura 8 - Contribuição de $E_{1}$ para o total $E_{\text {ir quando }} n_{\max }=350 \ldots \ldots \ldots \ldots . .37$

Figura 9 - Contribuição de $E_{1}$ para o total $E_{\text {ir }}$ quando $n_{\max }=500 \ldots \ldots \ldots \ldots .37$

Figura 10 - Consumo em função de $Z$, para $K=2$, com $n_{\max }=250 \ldots \ldots \ldots . . .38$

Figura 11 - Consumo em função de $Z$, para os seus respectivos $K$ ótimos, com $n_{\max }=$

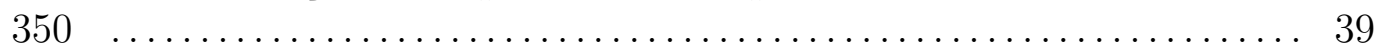

Figura 12 - Consumo em função de $Z$, para $K=1$, com $n_{\max }=500 \ldots \ldots \ldots \ldots .40$

Figura 13 - Proporção $\alpha_{z}$ aplicada sobre $n_{\text {ca }}$, para $n_{\max }=250 \ldots \ldots \ldots \ldots \ldots \ldots . \ldots 1$

Figura 14 - Proporção $\alpha_{\mathrm{z}}$ aplicada sobre $n_{\text {ca }}$, para $n_{\max }=350 \ldots \ldots \ldots \ldots \ldots \ldots . \ldots 2$

Figura 15 - Proporção $\alpha_{\mathrm{z}}$ aplicada sobre $n_{\text {ca }}$, para $n_{\max }=500 \ldots \ldots \ldots \ldots \ldots . .42$

Figura 16 - Proporção $\alpha_{z}$, para $K=1$ e $K=2$, e $n_{\max }=350 \ldots \ldots \ldots \ldots \ldots \ldots$ 


\section{LISTA DE SIGLAS}

\begin{tabular}{|c|c|}
\hline $4 \mathrm{G}$ & Quarta Geração das Redes Móveis \\
\hline $5 \mathrm{G}$ & Quinta Geração das Redes Móveis \\
\hline ARQ & Automatic Repeat reQuest \\
\hline C-ITS & Cooperative Intelligent Transport System \\
\hline CACC & Cooperative Adaptive Cruise Control \\
\hline CC-HARQ & Chase Combining Hybrid Automatic Repeat reQuest \\
\hline cMTC & Critical MTC \\
\hline DSCR & Dedicated Short Range Communication \\
\hline $\mathrm{E} 2 \mathrm{E}$ & End-to-end \\
\hline eMBB & Enhanced Mobile BroadBand \\
\hline FEC & Forward Error Control \\
\hline HARQ & Hybrid Automatic Repeat reQuest \\
\hline HARQ & Hybrid Automatic Repeat reQuest \\
\hline HetVNET & Heterogeneous Vehicular NETwork \\
\hline IR-HARQ & Incremental Redundancy Hybrid Automatic Repeat reQuest \\
\hline ITS & Intelligent Transport Systems \\
\hline LTE & Long Term Evolution \\
\hline METIS & $\begin{array}{l}\text { Mobile and wireless communication Enablers for the Twenty-twenty } \\
\text { Information Societ }\end{array}$ \\
\hline mMTC & Massive $M T C$ \\
\hline $\mathrm{MRC}$ & Maximum Ratio Combining \\
\hline MTC & Machine-type Communication \\
\hline NCS & Networked Control System \\
\hline $\mathrm{PPC}$ & Packetized Predictive Control \\
\hline $\mathrm{PPC}$ & Packetized Predictive Control \\
\hline S-HARQ & Simple Hybrid Automatic Repeat reQuest \\
\hline SARTRE & SAfe Road TRains for the Environment \\
\hline $\mathrm{TI}$ & Tactile Internet \\
\hline URC-L & URC over a long term \\
\hline URC-S & URC in a short term \\
\hline URC & Ultra-Reliable Communication \\
\hline URLLC & Ultra-Reliable Low-Latency Communication \\
\hline V2I & Vehicle to infrastructure communication \\
\hline $\mathrm{V} 2 \mathrm{~V}$ & Vehicle to vehicle communication \\
\hline $\mathrm{V} 2 \mathrm{X}$ & Vehicle to everything communication \\
\hline VANETs & Vehicular Ad hoc NETworks \\
\hline WLAN & Wireless Local Area Network \\
\hline WNCS & Wireless Networked Control System \\
\hline
\end{tabular}




\section{LISTA DE SÍMBOLOS}

\begin{tabular}{|c|c|}
\hline$B$ & Banda \\
\hline$\gamma$ & Relação sinal-ruído \\
\hline$n$ & Comprimento de pacote \\
\hline$\epsilon$ & Probabilidade de erro de pacote \\
\hline$C$ & Capacidade ergódica do canal \\
\hline$V$ & Dispersão do canal \\
\hline$Q$ & Função Gaussiana \\
\hline$K$ & Comprimento de predição \\
\hline$i$ & Índice do intervalo de tempo \\
\hline$u_{K}$ & Comando de controle preditivo \\
\hline$z$ & Número da transmissão \\
\hline $\mathbf{U}$ & Sequência de comandos de controle \\
\hline$H$ & Comprimento do cabeçalho do pacote em bits \\
\hline$L$ & Comprimento de cada comando em bits \\
\hline$p_{e}$ & Probabilidade de erro do pacote \\
\hline$R$ & Taxa de transmissão máxima para pacotes curtos \\
\hline$C$ & Capacidade do canal de Shannon \\
\hline$\gamma$ & Relação sinal-ruído \\
\hline$V$ & Dispersão do canal \\
\hline$P$ & Potência de transmissão \\
\hline G & Ganho do canal sem fio \\
\hline$N_{0}$ & Densidade espectral do ruído branco aditivo \\
\hline$B$ & Largura de banda \\
\hline$n$ & Número de usos de canal \\
\hline$T$ & Latência máxima admitida pelo sistema de controle \\
\hline$n_{\max }$ & Número máximo de usos de canal \\
\hline$p_{c}$ & Probabilidade de interrupção no controle \\
\hline$Z$ & Número máximo de transmissões \\
\hline$n_{\mathrm{ca}}$ & Número de usos de canal disponíveis para as $Z$ transmissões \\
\hline$n_{\text {ack }}$ & Número de símbolos da mensagem ACK \\
\hline$\alpha_{\mathrm{z}}$ & Porcentagem de $n_{\text {ca }}$ empregada para cada tentativa de transmissão \\
\hline$P_{\text {ir }}$ & $\begin{array}{l}\text { Potência de transmissão demandada para atender à probabilidade de } \\
\text { interrupção no controle }\end{array}$ \\
\hline$p_{\mathrm{e}, \mathrm{z}}$ & Probabilidade de erro de pacote relativa à transmissão $z$ \\
\hline$p_{\text {ack }}$ & Probabilidade de erro do ACK \\
\hline$E_{\text {ir }}$ & Energia total consumida \\
\hline$E_{z}$ & Componente energética relativa à transmissão $z$ \\
\hline$P^{\star}$ & Potência de transmissão ótima \\
\hline$n^{\star}$ & Comprimento ótimo do bloco \\
\hline$P_{\text {ack }}$ & Potência de transmissão do ACK \\
\hline
\end{tabular}




\section{SUMÁRIO}

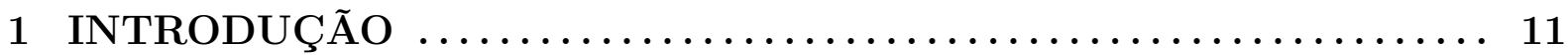

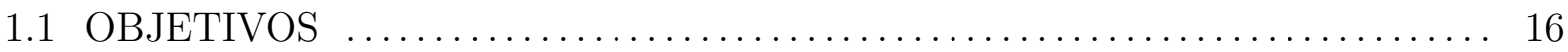

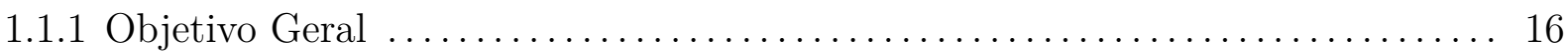

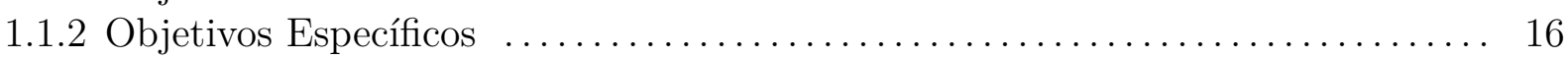

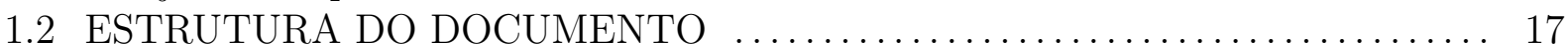

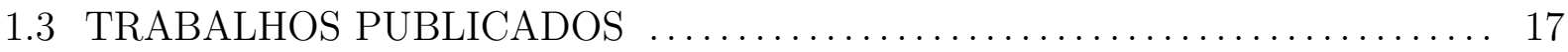

2 CONTEXTUALIZAÇÃO TEÓRICA $\ldots \ldots \ldots \ldots \ldots \ldots \ldots \ldots \ldots \ldots \ldots \ldots \ldots \ldots$

2.1 REQUISITOS E CARACTERÍSTICAS DE URLLC $\ldots \ldots \ldots \ldots \ldots \ldots \ldots \ldots \ldots$

2.2 CARACTERIZAÇÃO DOS PACOTES CURTOS $\ldots \ldots \ldots \ldots \ldots \ldots \ldots \ldots \ldots \ldots \ldots \ldots$

2.3 PROJETO DE SISTEMAS DE CONTROLE VIA REDE SEM FIO $\ldots \ldots \ldots .20$

2.4 TÉCNICA DE CONTROLE PREDITIVO EM PACOTES - PPC ........... 21

2.5 MECANISMO DE RETRANSMISSÃO E CORREÇÃO DE ERROS - HARQ . 23

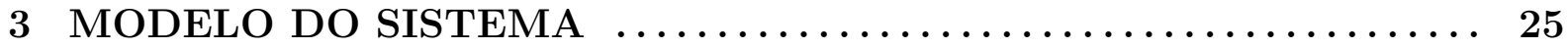

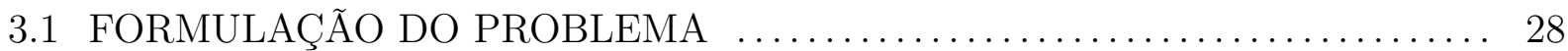

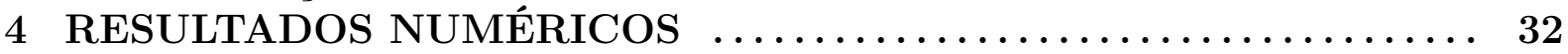

4.1 COMPRIMENTO DO COMANDO DE CONTROLE PREDITIVO $\ldots \ldots \ldots \ldots 33$

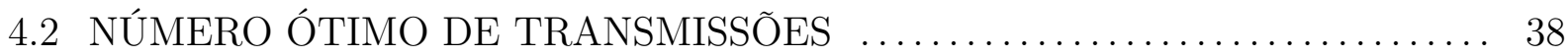

4.3 AVALIAÇÃO DO NÚMERO DE USOS DE CANAL $\ldots \ldots \ldots \ldots \ldots \ldots \ldots \ldots$

5 CONCLUSÕES E TRABALHOS FUTUROS $\ldots \ldots \ldots \ldots \ldots \ldots \ldots .44$

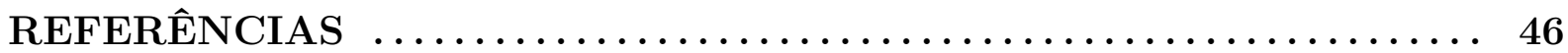




\section{INTRODUÇÃO}

Atualmente, as pessoas querem dos veículos muito mais do que qualidade e confiabilidade. É desejado que evoluam para serem proativos e cooperativos, de modo a contribuírem para a segurança e para uma mobilidade mais inteligente e sustentável. Em resposta a isto, podem-se observar duas tendências nos esforços da indústria automobilística: direção autônoma e serviços para segurança e eficiência no tráfego. Para que isso seja possível, veículos precisam captar e compartilhar informações. Sem comunicação entre veículos (V2V, do inglês Vehicle to vehicle communication), ou de veículo com a infraestrutura (V2I, do inglês Vehicle to infrastructure communication), estes veículos se tornam ilhas de informação. Assim sendo, esta já é vista como a próxima fronteira para a revolução automotiva, bem como um fator chave para a evolução dos sistemas de transporte inteligentes (ITSs, do inglês Intelligent Transport Systems) (LU et al., 2014).

Na comunicação V2V ocorre o compartilhamento de dados captados por sensores, produzidos pelas unidades de controle ou gerados pelos usuários, entre veículos próximos. A partir de informações como posição, velocidade e aceleração, é possível criar alertas ou respostas a eventos como mudanças de faixa ou frenagens bruscas, contribuindo para uma direção mais segura. A comunicação V2I permite que informações sejam compartilhadas mais amplamente. Assim como características da via podem ser transmitidas, dados provenientes de veículos podem ser encaminhados a usuários mais distantes.

Um exemplo de ITS dependente dos avanços nas redes veiculares é o comboio de veículos (platooning), que pode ser definido como um grupo de veículos que viajam juntos, ativamente coordenados em formação (LU et al., 2014). Baseado na tecnologia de controle de cruzeiro cooperativo adaptativo (CACC), o sistema trará melhorias na segurança rodoviária, fluxo no tráfego, redução do consumo de combustível e consequentemente de emissões. Nesta aplicação, o primeiro veículo poderia ser pilotado por um motorista, ou ser conduzido de forma autônoma, e os demais o seguiriam em comboio. Uma vez no comboio, o motorista do veículo pode relaxar e fazer outras tarefas, como se alimentar ou ler, proporcionando uma ótima experiência de direção, além de contribuir para a redução no número de acidentes. Empresas já estão trabalhando no assunto, como por exemplo a empresa Peloton Technology®, fundada em 2011 e focada no desenvolvimento destes sistemas (Peloton Technology, 2018). O projeto SARTRE também é uma referência (SARTRE, 2018). Diversas montadoras também participaram do 
European Truck Platooning Challenge colocando seus caminhões em trânsito em rodovias públicas europeias em 2016. Alguns trechos de rodovia denominados ITS-corridors foram preparados para comunicação V2I, que entre outros alertas, permitia avisar sobre situações de perigo na rodovia (European Truck Platooning, 2018). Outros exemplos são os projetos Sweden4Platooning e ENSEMBLE, elaborados com o objetivo de criar um ambiente propício para o desenvolvimento e a utilização de platooning entre veículos de marcas diferentes na Europa (SWEDEN4PLATOONING, 2020) (HORIZON2020, 2020). Há uma alta dependência de um sistema de comunicação confiável e com uma baixa latência para que essa técnica se desenvolva. Quanto mais próximos os participantes do comboio estão uns dos outros, maior a redução de consumo de combustível, no entanto, mais rápidas precisam ser as reações, restringindo mais os requisitos de latência da comunicação.

As comunicações V2V e V2I, baseadas em tecnologias wireless local area network (WLAN), são definidas como vehicular ad hoc networks (VANETs). O termo foi originalmente adotado para refletir a natureza ad hoc destas redes altamente dinâmicas (HARTENSTEIN; LABERTEAUX, 2008). Este tipo de rede é composto por um grupo de nós, em que cada um pode se comunicar diretamente com os demais sem a necessidade de um ponto de acesso centralizador, conferindo a ela a característica de rede dinâmica (Sharmila; Shanthi, 2016). A obtenção da confiabilidade necessária nas redes veiculares é um desafio caso se utilize somente um enlace sem fio devido à grande velocidade relativa entre transmissores e receptores e às mudanças de topologia da rede. A fim de se prover os requisitos de transmissão nas VANETs, long term evolution (LTE), ou 4G, e dedicated short range communication (DSCR) vêm sendo considerados. No entanto, ambas possuem algumas limitações. Desta forma, hoje se faz uso de uma combinação de tipos de enlace disponíveis, denominado por redes veiculares heterogêneas (HetVNETs) (ZHENG et al., 2015). As HetVNETs integram DSRC com redes celulares, podendo, com esta combinação, suportar as demandas de ITS.

Como a infraestrutura de redes celulares foi amplamente implantada nas últimas décadas, é economicamente eficiente utilizá-las para suportar a comunicação V2I (KIHL et al., 2012; CHENG et al., 2011), além de haver grande cobertura nas áreas urbanas, onde estão grande parte dos veículos. No entanto, com o aumento do número de veículos, as redes de quarta geração $(4 \mathrm{G})$ ou LTE são facilmente sobrecarregadas.

Até o momento, cada nova geração de sistemas celulares foi focada em aumentar a taxa de dados. A nova geração precisa atender às demandas advindas dos dispositivos e sensores que estarão conectados à rede. A essência do conceito de sistema do $5 \mathrm{G}$ está 
baseada em três tipos de uso importantes: melhora da banda larga (eMBB), comunicação de máquina massiva (mMTC) e comunicação de máquina crítica (cMTC) (TULLBERG et al., 2016).

Assim sendo, sistemas 5G não vão somente ter que superar as gerações anteriores em requisitos relacionados à taxa de dados e capacidade, mas também terão que endereçar estes novos cenários de utilização de MTC (ANDREWS et al., 2014). Com o objetivo de desenvolver o conceito da nova geração de sistemas celulares para suas mais diversas formas de utilização, o projeto METIS foi criado (OSSEIRAN et al., 2014). Uma das entregas deste projeto foi uma lista de cenários possíveis da utilização do $5 \mathrm{G}$ e os principais desafios relevantes para o seu desenvolvimento, não servindo somente como um guia técnico, mas também como forma de harmonização dos trabalhos de comunidades externas de pesquisa. Um destes cenários corresponde à melhoria da eficiência e segurança no tráfego pelo uso de comunicação de veículos para tudo (V2X) através de ITS cooperativo (C-ITS, do inglês Cooperative Intelligent Transport System), como é o caso do platooning, mencionado anteriormente.

No exemplo do projeto Sweden4Platooning, um protocolo utilizando DSRC (ou IEEE 802.11p) foi empregado na comunicação entre os veículos em um comboio de caminhões das empresas Volvo®e Scania®. Este padrão foi avaliado por Shah et al. (2018), em que os autores descrevem as limitações dos padrões existentes no cumprimento dos principais requisitos das comunicações veiculares emergentes, e os recursos da arquitetura $5 \mathrm{G}$ que são promissores para a solução destas questões.

Os requisitos de latência e confiabilidade deste tipo de comunicação, assim como de diversas outras aplicações, caracterizam uma ultra-reliable low latency communication (URLLC). De acordo com Popovski et al. (2019), a área automotiva representa um segmento importante e pode ser dividido em direção assistida, cooperativa e tele-operada, com requisitos de latência variando entre 5 e 20 ms, e confiabilidade de 99,999\%. Além disso, a comunicação V2V é considerada uma aplicação de URLLC nativa, pois não possui precedente na comunicação cabeada. Em outro caso citado pelos autores, da aplicação na Indústria 4.0 no controle de movimento, automação fabril ou automação de processos, a latência end-to-end (E2E) é ainda menor, em torno de $1 \mathrm{~ms}$, para o mesmo nível de confiabilidade.

Estes exemplos, uma vez que a transmissão de comandos do controle em tempo real é realizada através de um canal sem fio, podem ser definidos como sistemas de controle via rede sem fio (WNCSs, do inglês Wireless Networked Control System). 
Um WNCS pode ser descrito como um conjunto de sensores, controladores e atuadores que interagem através de uma rede sem fio para a realização do controle em malha fechada. A sua utilização traz vários benefícios, como flexibilidade, redução dos custos de instalação e manutenção, e melhoria na segurança, o que têm tornado esta uma tecnologia fundamental para aplicações em sistemas de controle críticos, uma vez que estes utilizam controle em tempo real de sistemas físicos através da rede. Este é o caso de muitas aplicações, como por exemplo, sistemas de controle aviônicos, de gestão predial, além dos já mencionados, automação industrial, Indústria 4.0 e sistemas veiculares (PARK et al., 2018). Além disso, o número de dispositivos conectados à rede é crescente, estimando-se que até 2025 estes sejam 5 bilhões (ERICSSON, January 2020), dando espaço a novas oportunidades.

No entanto, o uso de redes sem fio em sistemas de controle acarreta um atraso e uma probabilidade de erro de mensagem a cada transmissão, diferentemente dos sistemas convencionais de controle cabeados, que supõem uma entrega instantânea e uma confiabilidade extremamente elevada. Falhas de transmissão ou atraso no envio impactam diretamente no desempenho de um sistema, podendo gerar perdas econômicas ou até mesmo riscos à segurança, especialmente nos de comunicação crítica, que demandam alta confiabilidade para valores baixos de latência, motivando o estudo deste tipo de comunicação (BELLO et al., 2017).

De acordo com a teoria clássica, é possível realizar uma comunicação confiável em um canal ruidoso através da utilização de um código corretor de erro, desde que o comprimento seja grande o suficiente (SHANNON, 1948). Devido à restrição de latência, essa teoria não é aplicável à URLLC, uma vez que o número de usos de canal é limitado pela latência imposta, tornando-a mais desafiadora (POPOVSKI et al., 2018).

Outro complicador é o tipo de tráfego gerado na comunicação entre os componentes presentes nos WNCSs, na forma de pacotes curtos. Estes representam a forma mais comum de tráfego gerado na comunicação de máquina. Neste caso, o cabeçalho (metadata) pode ter o mesmo tamanho que os dados da mensagem (payload), para os quais os métodos tradicionais de transmissão não são apropriados. Em (DURISI et al., 2016), os autores apresentaram uma revisão dos princípios teóricos que governam a transmissão de pacotes curtos e como estes desenvolvimentos vão impactar o design de sistemas de comunicação sem fio futuros, bem como métricas que permitem avaliar o desempenho destas redes.

Ainda, Zhao et al. (2019) demonstram a importância de realizar um projeto 
conjunto dos sistemas de controle e comunicação citando como exemplo a taxa de amostragem que quanto maior, melhor o desempenho do controle. Por outro lado, ao aumentar a taxa muitos pacotes de dados são gerados, aumentando o tráfego na rede, podendo ocasionar maior perda de pacotes e atraso na transmissão, o que acaba impactando negativamente o realização do controle. Conclui-se então que existe um valor ótimo para a amostragem que pode ser encontrado no projeto conjunto dos sistemas.

Reafirmando essa necessidade, Park et al. (2018) apresentam a interação entre as variáveis de ambos, como amostragem, perda de pacotes, atraso e consumo, o que motiva sua sintonia em conjunto.

Em um WNCS o objetivo principal é transmitir uma ação de controle, em vez de entregar um fluxo de bits. Com este objetivo, Tong et al. (2018) emprega o controle preditivo em pacotes (PPC), método em que o controlador, baseado no estado da planta, além do comando de controle atual, também prevê e transmite comandos futuros, do controle preditivo, então armazenados em um buffer. Desta forma, habilita a operação do atuador mesmo que ocorra uma falha na transmissão, por meio do uso da sequência de comandos anteriormente enviada.

Com esta estratégia, os autores de Tong et al. (2018) mostram que é possível aumentar o tráfego na rede sem fio e, ao mesmo tempo, reduzir a utilização de recursos através de uma otimização do comprimento de comandos de controle preditivos. Isto contraria a suposição mais óbvia de que um aumento das demandas da comunicação resulta, inevitavelmente, em um aumento no consumo.

Em continuidade aos trabalhos desenvolvidos por Zhao et al. (2019) e Tong et al. (2018), Silva et al. (2020) oferecem uma relevante contribuição em relação à redução do consumo dos recursos sem fio ao empregar a técnica de hybrid automatic repeat request (HARQ), anteriormente avaliada no contexto de URLLC por Nadas et al. (2019). No método proposto, com a possibilidade de uma retransmissão em caso de erro, detectado através de uma requisição enviada pelo decodificador, apenas uma porção dos usos de canal disponíveis é empregada na primeira tentativa de envio. No caso de uma transmissão bem sucedida, o transmissor é desligado pelo restante do intervalo, promovendo uma economia de energia.

Apenas no caso de uma falha na transmissão, ou no recebimento de uma requisição de retransmissão, a totalidade de usos de canal é empregada. O resultado, considerando o comprimento ótimo de comandos de controle preditivos neste modelo, foi uma significativa redução de até $45 \%$ no consumo de recursos. Apesar da economia obtida por Silva et al. 
(2020), o estudo se limita a uma retransmissão, não avaliando se o ganho poderia ser maior ao aumentar essa quantidade.

\subsection{OBJETIVOS}

\subsubsection{Objetivo Geral}

O objetivo deste trabalho é analisar a contribuição da utilização de HARQ com mais de uma retransmissão para a minimização do consumo de recursos da comunicação sem fio em um WNCS, empregando PPC e o equacionamento aplicável a pacotes curtos, no projeto conjunto de sistema de comunicação e de controle para o cumprimento dos requisitos de URLLC.

\subsubsection{Objetivos Específicos}

- Pesquisar a respeito das novas demandas para os sistemas de comunicação sem fio, as novas aplicações e os requisitos de URLLC;

- Compreender o equacionamento e as métricas para pacotes curtos;

- Estudar os sistemas de controle via rede sem fio;

- Entender e aplicar o método de PPC utilizado por Tong et al. (2018) como ferramenta para aumentar a robustez nos WNCSs e minimizar o consumo de recursos sem fio, através do projeto combinado de sistema de comunicação e de controle;

- Estudar e reproduzir a estratégia de Silva et al. (2020) para uma maior redução do consumo ao empregar HARQ de redundância incremental com uma retransmissão;

- Estender o estudo de Silva et al. (2020) para mais retransmissões, empregando apenas uma fração dos usos de canal disponíveis a cada tentativa, e formular o equacionamento da energia total consumida na transmissão;

- Realizar simulações para obtenção do número ótimo de transmissões e do comprimento ótimo de comandos de controle preditivos, minimizando o consumo sem deixar de atender aos requisitos de URLLC;

- Avaliar a contribuição do trabalho pela comparação com os resultados obtidos por Tong et al. (2018) e Nadas et al. (2017). 


\subsection{ESTRUTURA DO DOCUMENTO}

O restante deste documento está organizado da seguinte forma. O Capítulo 2 mostra os conceitos que serão empregados no trabalho, apresentando a fundamentação teórica em um nível adequado para a compreensão da proposta, passando pela definição de URLLC, pacotes curtos, sistemas de controle via rede sem fio, controle preditivo por pacotes e HARQ. O Capítulo 3 descreve o modelo do sistema em questão e apresenta a formulação do problema, detalhando o equacionamento envolvido no problema de otimização a ser tratado. No Capítulo 4, as variáveis de entrada da simulação são informadas e os resultados são discutidos, abordando quais foram os valores ótimos encontrados para os fatores avaliados, qual foi o ganho em eficiência energética com a estratégia adotada, bem como a justificativa para os comportamentos observados. Por fim, o Capítulo 5 conclui o trabalho, apresentando as considerações finais, enfatizando os resultados obtidos e propondo possíveis extensões desta pesquisa.

\subsection{TRABALHOS PUBLICADOS}

Com relação ao tema desta dissertação, a seguinte publicação foi obtida:

- IAREMCZUK, A. L. V.; MORITZ, G.; SOUZA, R. D.; BRANTE, G. Otimização do Consumo Energético em Sistemas de Controle sem Fio Através de Controle Preditivo e Redundância Incremental. XXXVIII Simpósio Brasileiro de Telecomunicações e Processamento de Sinais, 22-25 Novembro, 2020.

Além desta, ao longo da realização deste trabalho, houve a participação como coautora na publicação abaixo:

- SILVA, F. E. da; IAREMCZUK, A. L. V.; SOUZA, R. D.; BRANTE, G.; MORITZ, G. L.; HUSSAIN, S. Hybrid arq in wireless packetized predictive control. IEEE Sensors Letters, v. 4, n. 5, p. 1-4, 2020. 


\section{CONTEXTUALIZAÇÃO TEÓRICA}

Neste capítulo serão apresentados os principais conceitos teóricos aplicados neste trabalho, provendo de forma sucinta o embasamento necessário para a compreensão do modelo que será proposto e das análises realizadas a partir dos Capítulos 3, 4 e 5.

\subsection{REQUISITOS E CARACTERÍSTICAS DE URLLC}

Pode-se dizer que a quinta geração de redes móveis tem como principal diferença em relação às anteriores o fato de nativamente endereçar dois modos genéricos de comunicação de máquina: a mMTC e a URLLC (Ultra-Reliable Low Latency Communication) (POPOVSKI et al., 2018). URC vinha sendo o termo utilizado para descrever a demanda do $5 \mathrm{G}$ de que um certo nível de serviço de comunicação deve estar disponível quase $100 \%$ do tempo. Esta é ainda classificada em dois tipos diferentes: URC-L e URC-S. O primeiro se preocupa em garantir uma confiabilidade de quase $100 \%$, disponibilizando uma certa taxa de dados para um grande número de usuários enquanto que o segundo, mantendo os mesmos níveis de confiabilidade, busca atender a requisitos restritivos de latência, abaixo de $10 \mathrm{~ms}$ (POPOVSKI, 2014). A URLLC, que de certa forma está contida na anteriormente definida URC-S, vem se estabelecendo como um conceito na comunidade e sendo mais amplamente discutida e estudada do que os conceitos anteriores. Esta está relacionada a latências ainda menores, da ordem de $1 \mathrm{~ms}$, e confiabilidade superior a 99.999\% (POPOVSKI et al., 2019).

Popovski et al. (2018) consideram que URLLC é o elemento mais inovador a ser incorporado ao $5 \mathrm{G}$, sendo que além de aplicações como controle remoto de robôs ou coordenação entre veículos, muitas novas possibilidades surgirão, com utilizações que ainda são desconhecidas. Atingir ultra-confiabilidade e ultra-baixa latência é a base para diversas aplicações de missão crítica, como a automação industrial, internet tática (TI), direção remota, realidade virtual e tele-cirurgia, e como alcançar estes dois requisitos conflitantes ao mesmo tempo é uma questão em aberto (HOU et al., 2020). Por exemplo, devido às restrições de latência, o número de usos de canal disponíveis é limitado, e assim, códigos corretores de erro longos não podem ser utilizados para fornecer uma alta confiabilidade (POPOVSKI et al., 2018). As aplicações citadas, com uso potencial de URLLC, bem como a definição dos seus requisitos de confiabilidade e latência, foram levantados por Chen et al. (2018), assim como os fatores que consideram os principais 
desafios de projeto.

Para as aplicações mencionadas, devido ao tipo de pacote gerado na comunicação entre os elementos integrantes destes sistemas, além dos requisitos restritivos, o projeto deve levar em conta um equacionamento específico, conforme será abordado na Seção 2.2.

\subsection{CARACTERIZAÇÃO DOS PACOTES CURTOS}

O projeto dos sistemas de transmissão sem fio atuais está baseado na suposição de que a informação de controle ou cabeçalho tem tamanho desprezível em comparação aos dados. No entanto, a forma mais comum de tráfego gerado por sensores consiste em pacotes curtos. Para estes, os resultados da teoria clássica da informação e suas métricas, capacity (SHANNON, 1948) e outage capacity (OZAROW et al., 1994), não são precisas, pois estas se baseiam no fato de que o ruído térmico e as distorções introduzidas pela propagação no canal são minimizados, de acordo com a Lei dos grandes números. Além disso, a teoria clássica mostra que uma codificação de canal adequada permite uma transmissão confiável a taxas próximas da capacidade nestes casos, que pode ser calculada através de

$$
C=B \log _{2}(1+\gamma)
$$

em que $B$ corresponde à banda e $\gamma$ à relação sinal-ruído.

Já para os pacotes curtos, uma codificação inadequada dos dados de cabeçalho afeta significantemente a qualidade da transmissão (DURISI et al., 2016). Com isso, em (POLYANSKIY et al., 2010), (YANG et al., 2013) e (DURISI et al., 2016) é proposto o cálculo de uma máxima taxa de transmissão para pacotes curtos, para a qual exista um par codificador/decodificador, dado um comprimento de pacote ou número de usos do canal $n$, em que a probabilidade de erro não exceda $\epsilon$, expressado como

$$
R^{*}(n, \epsilon)=C-\sqrt{\frac{V}{n}} Q^{-1}(\epsilon)+\mathcal{O}\left(\frac{\log _{2} n}{n}\right)
$$

em que $C$ é a capacidade ergódica do canal, $V=1-2^{-2 C}$ é a dispersão do canal, $Q^{-1}$ é o inverso da função Gaussiana $Q(x)$, que é a probabilidade de uma variável aleatória com distribuição normal ser maior que $x$, e $\mathcal{O}\left(\frac{\log _{2} n}{n}\right)$ são termos da ordem $\frac{\log _{2} n}{n}$.

Isso significa que no caso dos pacotes curtos, para atender a uma probabilidade máxima de erro $\epsilon$ com $n$ usos de canal, haverá sempre uma diminuição da taxa proporcional a $1 / \sqrt{n}$ em comparação à capacidade $C$ de Shannon (1948). 
Este é o equacionamento em que este trabalho está baseado, uma vez que o modelo do sistema de controle proposto, objeto deste estudo, possui dispositivos se comunicando através de pacotes curtos por um canal sem fio. Este tipo de sistema de controle envolvendo comunicação sem fio será descrito na Seção 2.3.

\subsection{PROJETO DE SISTEMAS DE CONTROLE VIA REDE SEM FIO}

Um sistema de controle via rede sem fio (WNCS) consiste em um sistema de controle em malha fechada em que sensor e controlador, e/ou controlador e atuador são conectados através de uma rede sem fio, em vez das convencionais redes cabeadas. Existem várias vantagens em comparação aos tradicionais sistemas de controle via redes (NCSs, do inglês Networked Control Systems), como a já mencionada ausência ou redução de cabeamento, baixo custo, alta flexibilidade e empregabilidade para transmissões a longas distâncias (WANG et al., 2015).

Nos sistemas de controle convencionais, que utilizam cabos, assume-se que a entrega dos dados de leitura dos sensores, bem como dos comandos de controle, ocorrem de maneira instantânea, com altíssima confiabilidade (PARK et al., 2018). Já no caso das WNCSs, a comunicação sem fio implica em uma probabilidade de erro de transmissão não nula, devido a fatores que impactam na confiabilidade da transmissão, como o atraso no envio de pacotes, o meio de transmissão compartilhado, além erros de amostragem e quantização (SADI et al., 2014), fenômenos inevitáveis em redes, especialmente nas sem fio (ZHANG et al., 2013). Podem-se citar como exemplos de fenômenos que causam intercorrências, e prejudicam a comunicação, o tráfego ambiente no canal, o desvanecimento de bloco e por multipercurso (ULUSOY et al., 2011). Estes podem ser amenizados através da adição de mais redundância às mensagens, o que tem como consequência maiores atrasos.

Os efeitos descritos acima podem acarretar sérias consequências, dependendo do tipo de aplicação, desde impactos financeiros a de segurança. O controle em malha fechada do atuador depende do recebimento dos comandos dentro de um determinado intervalo limite, em segundos, ou até milissegundos, dependendo do sistema em questão, para que o funcionamento da planta não seja comprometido. Isso significa que o projeto de um WNCS precisa incluir mecanismos que aumentem a tolerância, ou robustez, em relação a perdas de mensagens ou atrasos, ao mesmo tempo que o sistema de comunicação deve atender às demandas específicas de confiabilidade e latência (PARK et al., 2018). 
Com requisitos geralmente restritivos de tempo e confiabilidade, o projeto de um WNCS se torna desafiador, uma vez que as propriedades adversas inerentes à comunicação sem fio, além do consumo energético limitado pela bateria dos nós, fazem com que estes sejam difíceis de se atingir (SADI et al., 2014).

Sendo assim, o projeto combinado de sistema de comunicação e controle se faz importante para a definição adequada dos parâmetros e métodos para otimização do consumo de recursos, sem que haja o comprometimento do desempenho ou do cumprimento dos requisitos.

Diversos autores utilizam esta abordagem. Por exemplo, no modelo utilizado por Scaciota et al. (2019), erros na comunicação influenciam na estabilidade do sistema. Através da utilização de average dwell-time, ou tempo médio de permanência nos subsistemas que representam a dinâmica da planta, e de um projeto combinado de comunicação e controle, os autores garantiram a estabilidade do sistema e ainda minimizaram o consumo energético por bit transmitido em até $96 \%$, em comparação ao projeto independente dos sistemas. Lin Xiao et al. (2003) realizaram a otimização do desempenho de um sistema linear ao alocar recursos de comunicação juntamente da definição dos parâmetros do controlador. Xiangheng Liu e Goldsmith (2004) propuseram uma estrutura cross-layer para o projeto conjunto de redes sem fio e controladores distribuídos, mostrando que a técnica promove ganhos de desempenho, enquanto que, alternativamente, o projeto separado de cada layer da comunicação poderia levar a uma instabilidade do sistema de controle. Zhao et al. (2019) utilizaram PPC como estudo de caso para demonstrar como, no projeto conjunto dos sistemas de controle e comunicação, a interação entre ambos é capturada, possibilitando a obtenção de valores otimizados para os parâmetros, reduzindo o consumo e, ao mesmo tempo, atendendo às demandas do controle. Esta é a técnica empregada neste trabalho e será explicada na Seção 2.4.

\subsection{TÉCNICA DE CONTROLE PREDITIVO EM PACOTES - PPC}

Em um sistema de comunicação sem fio, assume-se que quanto mais rigorosos os requisitos, com maior tráfego de informação ou confiabilidade, maior será o consumo de recursos. Da mesma forma, que uma flexibilização destes requisitos de transmissão implicaria diretamente em um menor consumo. No entanto, quando se trata de um WNCS, estas premissas não são necessariamente verdadeiras. Isso se deve ao fato de que, neste tipo de sistema, o objetivo está na execução dos comandos de controle, e não simplesmente na entrega de uma sequência de bits (TONG et al., 2018), podendo ser 
utilizados artifícios para a otimização do projeto dos mesmos.

Um dos mecanismos mais eficientes que pode ser empregado para se obter a robustez requerida em um WNCS é o PPC, ou controle preditivo em pacotes (XIE et al., 2019),(WANG et al., 2019), (WANG et al., 2015), (HUANG et al., 2011), (QIN; BADGWELL, 2003), (TONG et al., 2018), (SILVA et al., 2020). Com a sua aplicação, os requisitos para o sistema de comunicação podem ser flexibilizados, sem que ocorram prejuízos ao desempenho do sistema de controle.

Neste método, o controlador não apenas utiliza a leitura do sensor para fornecer um comando de controle com base no estado atual da planta, como também prevê os estados futuros do sistema. Isso possibilita o cálculo e envio de comandos de controle futuros ao atuador através de um pacote de dados transmitido pelo canal sem fio. Através do uso de um buffer, os comandos de controle futuros são armazenados, enquanto que o atual é executado. Este esquema faz com o sistema se torne mais tolerante a problemas na comunicação, uma vez que, no caso de um novo pacote não ser recebido corretamente, o buffer ainda contém comandos de controle do pacote anterior que podem ser utilizados pelo atuador, possibilitando que a tarefa de controle continue sem interrupção, o que flexibiliza as demandas para o sistema de comunicação (TONG et al., 2018).

De acordo com (WANG et al., 2019), existem dois métodos tradicionais de transmissão de pacotes em sistemas com PPC. O primeiro, denominado transmissão intermitente, transmite um novo pacote somente após o esgotamento dos comandos de controle armazenados no buffer que foram enviados no pacote anterior. Uma vez que ocorre o uso excessivo dos comandos armazenados, um bom desempenho do controle em tempo real se torna difícil de atingir. No entanto, a técnica economiza recursos sem fio. O segundo método, chamado de transmissão contínua, consiste em transmitir um novo pacote a cada intervalo de tempo, assegurando o controle em tempo real. No entanto, esta metodologia consome muitos recursos sem fio (de espectro e de energia). Com isso, conclui-se que ambas as alternativas não promovem uma boa solução para consumo e funcionamento ao mesmo tempo.

Desta forma, realizar um projeto conjunto de sistema de comunicação e de controle para obter um compromisso entre desempenho e eficiência é uma estratégia mais interessante, como em (TONG et al., 2018), em que ambos foram considerados ao se obter um valor otimizado para o número de comandos futuros a serem enviados ao controlador em um pacote para minimizar o consumo, sem deixar de atender aos requisitos de controle em tempo real. Estes resultados foram posteriormente estendidos por Silva et al. (2020) 
ao agregar um método de retransmissão de pacotes denominado HARQ.

\subsection{MECANISMO DE RETRANSMISSÃO E CORREÇÃO DE ERROS - HARQ}

Quando a taxa de erro de um sistema de transmissão não é aceitável, mecanismos de contenção se fazem necessários. Existem basicamente duas categorias de técnicas para esta finalidade: FEC, do inglês Forward Error Control, e ARQ, do inglês Automatic Repeat reQuest. A primeira utiliza códigos corretores de erro através da adição de bits de redundância para que o receptor tente determinar os locais com erros e realizar correções. Se houver sucesso, o pacote é corretamente decodificado. Do contrário, no caso de falha de decodificação, dados incorretos são entregues. Na segunda, um código com boa capacidade de deteç̧ão de erro é empregado. O receptor é então capaz de determinar se o pacote recebido está livre de erros e notificar o transmissor sobre uma correta decodificação, ou, caso contrário, solicitar uma retransmissão. Neste caso, a retransmissão é realizada até que uma detecção correta aconteça. Com esse método, dados errados só serão entregues caso haja um problema na detecção da presença de erros, o que pode ocorrer com uma probabilidade muito baixa quando utilizada uma codificação apropriada (LIN et al., 1984).

Ambos os métodos possuem inconvenientes. O uso de FEC pode adicionar mais redundância que realmente é necessário, ou pode ser difícil de se obter a confiabilidade requisitada. Por outro lado, o ARQ pode demandar transmissões demais caso ocorram muitas falhas. Além disso, o ARQ não apresenta uma entrega constante, e isso se intensifica se a taxa de erro do canal for elevada (LIN et al., 1984).

Alternativamente, Brayer (1968) propôs o esquema então denominado hybrid retransmission technique, atualmente conhecido por hybrid automatic repeat request (HARQ). Esta metodologia consiste em uma combinação de FEC com ARQ. Neste, o dado recebe um código detector de erros e então um código corretor de erros. A informação é então transmitida em blocos ao receptor, onde o processo de correção de erro é ativado. Depois da correção de erros, uma detecção final de erros residuais é realizada. Se ainda assim algum erro persistir, o bloco é rejeitado e uma retransmissão é solicitada pelo receptor. Este processo se repete até que a informação seja corretamente decodificada pelo receptor.

Existem diferentes tipos de HARQ, que podem ser classificados nas seguintes categorias (ZHANG, 2020):

- Tipo I - Consiste em HARQ sem combinação. O receptor descarta o pacote se a 
decodificação não foi bem sucedida e solicita uma nova transmissão até que a a decodificação tenha sucesso ou que um número limite de tentativas seja alcançado. Todos os pacotes contém os dados, ou seja, são auto-decodificáveis. Esse é o caso do S-HARQ;

- Tipo II - Para a decodificação, o receptor combina todos os pacotes recebidos. No entanto, os pacotes não são auto-decodificáveis. Como exemplo, pode-se utilizar o IR-HARQ. Neste, a primeira transmissão contém dados e bits de paridade. Se essa transmissão falha, apenas bits de paridade são enviados nos pacotes subsequentes. O receptor utiliza, então, o conteúdo de todos os envios para realizar a decodificação;

- Tipo III - O receptor combina todos os pacotes no momento da decodificação, porém, diferentemente do tipo II, todos os pacotes são auto-decodificáveis. Podese representá-lo pelo CC-HARQ, também chamado de HARQ por diversidade de repetição. Este utiliza uma mesma codificação a cada transmissão, ou seja, as retransmissões são iguais ao primeiro pacote. No entanto, utilizando MRC no receptor ao combinar todos os pacotes, melhora a qualidade da decodificação.

Pode-se considerar que os tipos II e III proveem redundância incremental, uma vez que cada retransmissão agrega informações redundantes para auxiliar o receptor na decodificação da mensagem.

A associação de PPC com HARQ de redundância incremental foi a estratégia adotada por Silva et al. (2020), considerando a possibilidade de uma retransmissão. O presente trabalho irá demonstrar os efeitos de expandir essa consideração para um número maior de retransmissões. 


\section{MODELO DO SISTEMA}

O modelo em questão consiste em um sistema que utiliza PPC, em que um controlador, em função das informações a respeito do estado atual da planta lidas por um sensor, contendo um comprimento de predição de $K$ comandos, gera uma sequência de comandos de controle dada por

$$
\mathbf{U}(i)=\left[u_{1}(i), u_{2}(i), \cdots, u_{K}(i)\right]
$$

em que $i$ é o índice do intervalo de tempo, $u_{1}(i)$ é o comando de controle para o intervalo atual e $\left[u_{2}(i), \cdots, u_{K}(i)\right]$ são os comandos preditivos para intervalos futuros.

O canal de comunicação entre controlador e decodificador é sem fio, sendo este um WNCS, e para ser capaz de armazenar comandos de controle futuros, um buffer é ligado ao atuador, como pode ser observado na Figura 1. O conjunto decodificador-buffer é responsável por fornecer os comandos recebidos ao atuador, através de uma ligação cabeada, a cada intervalo de tempo.

Figura 1 - Modelo do sistema de controle, em que o controlador e o atuador se comunicam através de uma rede sem fio

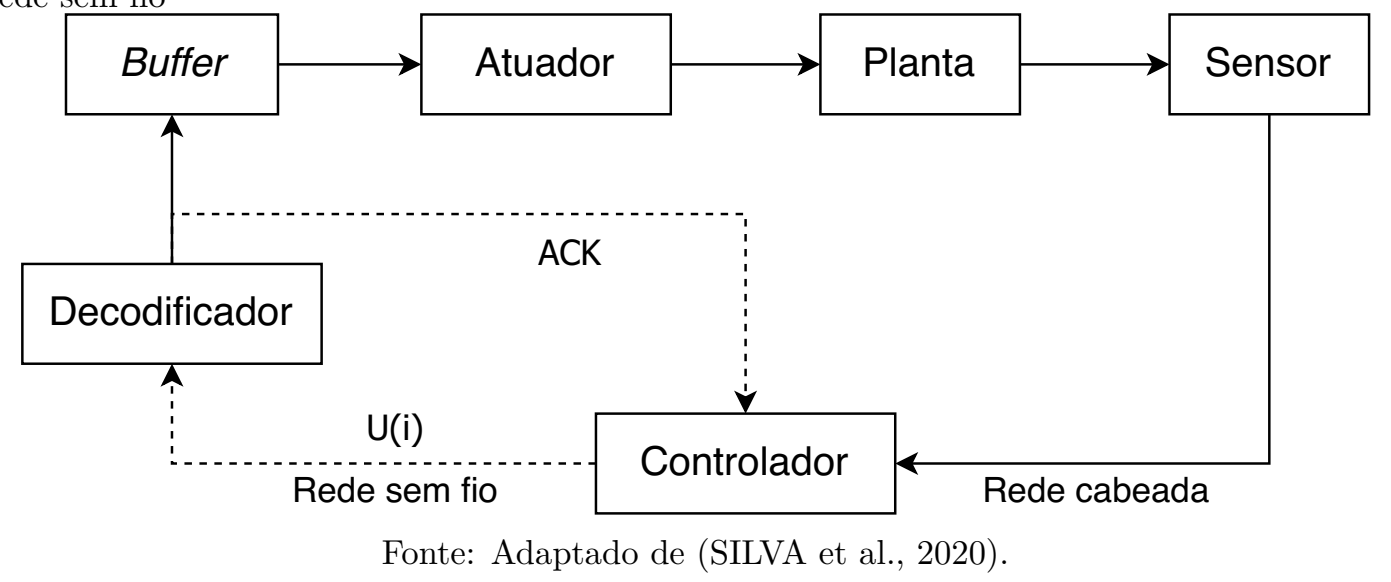

Com a utilização de HARQ, uma mensagem requisitando ou não uma retransmissão (ACK/NACK) é enviada pelo decodificador ao controlador através do canal sem fio a cada envio. Em (SILVA et al., 2020), com a possibilidade de apenas uma retransmissão, somente uma mensagem de retorno era necessária. Com a possibilidade de serem feitos mais envios, para cada $z$ transmissões, haverá $z-1$ mensagens ACK/NACK, sendo possível identificar se a comunicação foi bem sucedida a cada tentativa. Na última transmissão o retorno não é necessário, uma vez que, na ocorrência de um outage, o envio 
subsequente já será de uma nova sequência $\mathbf{U}(i+1)$.

Na situação em que ocorram falhas no envio, isto é, o não recebimento de um ACK para uma mensagem decodificada corretamente, ou ainda, um problema na decodificação sendo informado através de um NACK, novas tentativas podem ser realizadas até o número máximo de retransmissões estipulado. Estas retransmissões são realizadas sem que ocorra uma interrupção na comunicação, por perda de pacotes ou atraso.

Se mesmo após todas as tentativas de envio, não houver sucesso na transmissão do pacote, o atuador dispõe de uma sequência de $K-1$ comandos futuros armazenados no buffer, que poderá ser utilizada até que se reestabeleça a comunicação, sem que haja uma interrupção no controle.

Já no caso de uma tentativa de envio bem sucedida, ou seja, em que a mensagem foi corretamente decodificada e o ACK foi recebido pelo controlador, o transmissor é desligado, poupando a energia que seria empregada nas demais retransmissões durante o restante do intervalo. Vale observar que esta abordagem difere da proposta inicial de Tong et al. (2018), em que a redução do gasto energético é advinda unicamente da obtenção de valores ótimos quando PPC é empregado no projeto conjunto dos sistemas de comunicação e controle. Além de usufruir dos benefícios desta metodologia, pretende-se, com este sistema, minimizar o consumo através da utilização de um menor número de usos de canal para realizar a transmissão do pacote, como será detalhado na Seção 3.1.

Cada pacote possui um cabeçalho de $H$ bits e um payload definido em função do número de comandos de controle $K$ a serem enviados, sendo seu comprimento total (TONG et al., 2018)

$$
N=H+K L
$$

em que $L$ é o comprimento de cada comando, conforme ilustrado na Figura 2. Nela, pode-se observar que o tamanho do cabeçalho não é desprezível em comparação aos dados, característica dos pacotes curtos (DURISI et al., 2016).

Figura 2 - Estrutura do pacote contendo a sequência de comandos de controle

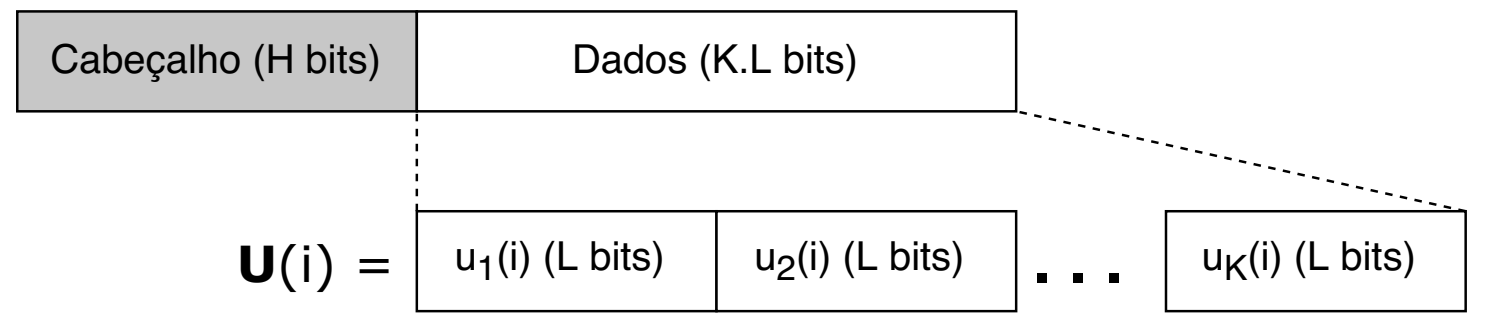

Fonte: Adaptado de (SILVA et al., 2020). 
Tratando-se de pacotes curtos, a capacidade de canal de Shannon não pode ser aplicada (GOLDSMITH, 2005), e é necessário adotar o equacionamento apresentado na Seção 2.2 para encontrar a taxa máxima de transmissão em função do comprimento $n$ do bloco e da probabilidade de erro do pacote $p_{e}$. Optou-se pela aproximação sugerida por Durisi et al. (2016), substituindo os termos de ordem logarítmica em (2) por $\frac{\log _{2} n}{2 n}$, sendo a taxa $R$ dada por

$$
R\left(n, p_{e}\right) \approx C-\sqrt{\frac{V}{n}} Q^{-1}\left(p_{e}\right)+\frac{\log _{2} n}{2 n},
$$

em que

$$
\begin{gathered}
C=\log _{2}(1+\gamma), \\
V=\gamma \frac{2+\gamma}{(1+\gamma)^{2}}\left(\log _{2} e\right)^{2} \approx\left(\log _{2} e\right)^{2} .
\end{gathered}
$$

Em (5), (6) e (7), C é a capacidade do canal de Shannon com banda unitária, $\gamma$ corresponde à relação sinal-ruído (SNR), $V$ é a dispersão do canal e $Q(x)$ é a probabilidade de uma variável aleatória com distribuição normal ser maior que $x$.

Sendo $P$ a potência de transmissão, $G$ o ganho do canal, $N_{0}$ a densidade espectral do ruído branco aditivo e $B$ a largura de banda, a SNR no decodificador é dada por

$$
\gamma=\frac{P G}{N_{0} B}
$$

Além disso, o número de usos de canal $n$, ou uso de recurso tempo-frequência em cada pacote, pode ser descrito por

$$
n=\frac{N}{R\left(n, p_{e}\right)},
$$

em que $n=B \cdot T$, sendo $T$ a latência máxima admitida pelo sistema de controle, variando entre 1 e $n_{\max }$, obedecendo à restrição de latência imposta pela sensibilidade ao atraso, característica deste tipo de sistema.

A probabilidade de erro de pacote pode ser calculada por

$$
p_{e} \approx Q\left(\frac{n C-N+\frac{\log _{2} n}{2}}{\sqrt{n V}}\right),
$$

obtida pela combinação de (9) e (5).

Neste tipo de modelo, conforme sugerido anteriormente, podem ocorrer $K-1$ perdas de pacotes até que o buffer esteja vazio e o atuador não tenha informações sobre o 
que executar na sequência, ou seja, uma interrupção no controle (control outage). Sendo $p_{e}$ a probabilidade de erro de pacote e assumindo que cada transmissão é independente, para garantir uma determinada probabilidade $p_{c}$ de interrupção no controle, deve-se obedecer à seguinte inequação (TONG et al., 2018)

$$
p_{e} \leq p_{c}^{\frac{1}{K}}
$$

Existe um compromisso entre $K$ e $p_{e}$, sendo que ao se escolher um $K$ pequeno, $p_{c}$ aumenta, uma vez que há menos comandos à disposição quando a transmissão é interrompida. Por outro lado, um $K$ muito grande eleva a $p_{e}$ devido à maior taxa de transmissão necessária, influenciando negativamente no $p_{c}$. Desta maneira, é necessário encontrar um valor ótimo para o comprimento de comandos de controle.

\subsection{FORMULAÇÃO DO PROBLEMA}

Este trabalho tem como objetivo diminuir o consumo energético envolvido na transmissão de um pacote. O método proposto consiste em aplicar HARQ de redundância incremental, dividindo os usos de canal entre $Z$ transmissões e $Z-1$ mensagens ACK, ou seja

$$
n_{\max }=n_{\mathrm{ca}}+(Z-1) \cdot n_{\mathrm{ack}},
$$

em que $n_{\max }$ é o número máximo de usos de canal, $n_{\text {ca }}$ é o número de usos de canal disponíveis para as $Z$ transmissões e $n_{\text {ack }}$ são os símbolos utilizados pela mensagem ACK.

Cada tentativa de transmissão $z \in\{1, \ldots, Z\}$ utiliza apenas uma porção dos usos do canal $n_{\text {ca }}$, que correspondem a

$$
n_{\mathrm{z}}=\left\lceil\alpha_{\mathrm{z}} n_{\mathrm{ca}}\right\rceil
$$

sendo $\alpha_{\mathrm{z}}$ uma constante definida entre 0 e 1 , que representa a porcentagem de $n_{\text {ca }}$ empregada para cada tentativa de transmissão $z \in\{1, \cdots, Z-1\}$, em que $\lceil x\rceil$ é o menor inteiro maior que $x$. Na última tentativa de envio $z=Z$, sendo esta a última oportunidade de transmissão dentro do intervalo $T$, utilizam-se todos os $n_{Z}$ usos de canal remanescentes. Consequentemente, pode-se afirmar que $\sum_{z=1}^{Z} \alpha_{z}=1$ e $\sum_{z=1}^{Z} n_{\mathrm{z}}=n_{\mathrm{ca}}$.

A estratégia para reduzir a utilização dos recursos da comunicação sem fio consiste em desligar o transmissor ao receber um ACK informando que a decodificação da zésima mensagem foi realizada com sucesso, poupando a energia por uma parcela de $T$, 
correspondente ao restante do intervalo. O mecanismo de transmissão está ilustrado na Figura 3, tomando como exemplo um número máximo de transmissões $Z=3$.

Figura 3 - Método para otimização do uso de recursos, empregando redundância incremental, em que cada tentativa de envio utiliza $\left\lceil\alpha_{\mathrm{z}} n_{\mathrm{ca}}\right\rceil$ usos de canal, para um número máximo de transmissões $Z=3$ : (a) economia de recursos após sucesso na primeira transmissão; (b) um problema na decodificação do pacote com uma nova solicitação através de um NACK, seguido de um problema de recebimento do ACK, resultando em $100 \%$ de utilização dos recursos

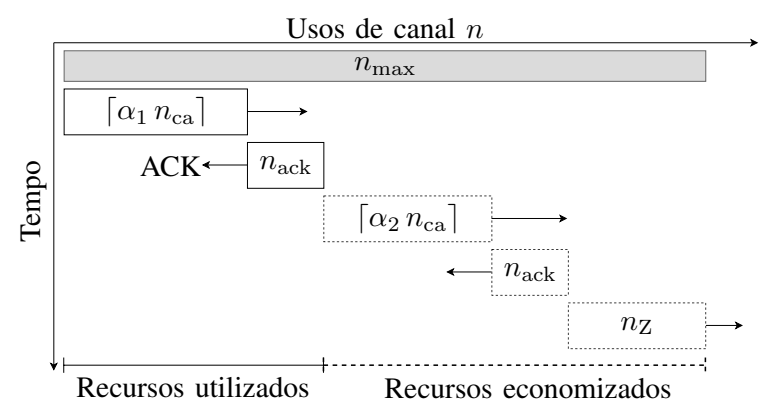

(a)

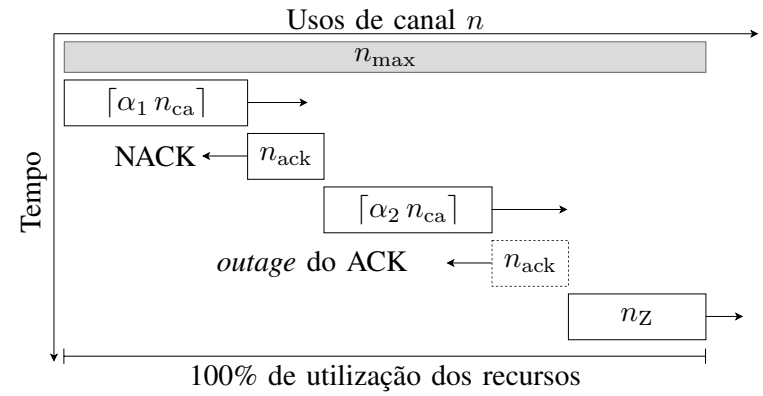

(b)

Fonte: Autoria própria.

A proporção $\alpha_{z}$ precisa ser selecionada estrategicamente para que a primeira transmissão tenha um outage controlado, de forma a ser complementado pelas rodadas subsequentes de redundância incremental, tal que a chance de sucesso na primeira transmissão seja relativamente grande, de modo a aumentar a probabilidade de não precisar das demais, mas não a ponto de exigir o consumo de quase todos os $n_{\text {ca }}$ usos do canal.

Pela combinação de (6), (8) e (10), isolando $P$ e utilizando o valor de $n_{\text {ca }}$ no lugar de $n$, é possível obter a potência de transmissão do pacote $P_{\text {ir }}$ demandada para atender à probabilidade de interrupção no controle $p_{c}$, ou seja, $p_{e}=p_{c}^{\frac{1}{K}}$.

Vale ressaltar que $P_{\text {ir }}$ neste método é maior do que em (TONG et al., 2018), que não previa envios de mensagem $\mathrm{ACK}$, pois os usos de canal $n_{\text {ack }}$ de cada uma das $Z-1$ mensagens precisam ser descontados. Como consequência, quanto maior $Z$, maior $P_{\text {ir }}$.

A partir de $P_{\text {ir }}$, podem-se encontrar os valores de $C, V$ e $\gamma$, com (6), (7) e (8), respectivamente, necessários para o cálculo da probabilidade de erro de pacote $p_{\mathrm{e}, \mathrm{z}}$ através de (10), considerando $n$ como os usos de canal utilizados até o $z$-ésimo envio. Essa é a probabilidade com a qual o decodificador solicitará uma nova transmissão.

Além do erro de pacote, assume-se que há uma probabilidade $p_{\text {ack }}$ de que o ACK não seja recebido pelo controlador, mesmo quando o pacote seja decodificado com sucesso. Neste caso, um novo envio é efetuado sem que haja uma solicitação por parte do 
decodificador.

O consumo energético realizado a cada tentativa de transmissão $z$ pode ser obtido por

$$
E_{\mathrm{z}}=\frac{P_{\mathrm{ir}} n_{\mathrm{z}}}{B}
$$

Também é necessário considerar a energia consumida pela mensagem ACK

$$
E_{\mathrm{ack}}=\frac{P_{\mathrm{ack}} n_{\mathrm{ack}}}{B}
$$

em que $P_{\text {ack }}$ é a sua potência de transmissão.

A energia total da transmissão $E_{\text {ir }}$ é calculada pela a combinação do consumo em diferentes situações com suas probabilidades de ocorrência. Estas podem ser elencadas como:

- Sucesso no recebimento do pacote e do ACK, com probabilidade $\left(1-p_{\mathrm{e}, \mathrm{z}}\right)\left(1-p_{\text {ack }}\right)$;

- Erro no recebimento do pacote, com probabilidade $p_{\mathrm{e}, \mathrm{z}}$;

- Falha no recebimento do ACK, com probabilidade $\left(1-p_{\mathrm{e}, \mathrm{z}}\right) p_{\text {ack }}$.

Os dois últimos casos irão resultar em um novo envio, sujeito às três situações supracitadas, em cascata, sucessivamente, até que seja atingido o limite de transmissões $Z$, em que a totalidade de usos de canal é empregada.

Conhecidas as componentes energéticas correspondentes a cada tentativa de envio, bem como a combinação de probabilidades para cada evento, é possível obter a energia total consumida $E_{\text {ir }}$, que pode ser escrita como

$$
E_{\mathrm{ir}}(Z)=\sum_{k=1}^{Z}\left(E_{k} \cdot \prod_{z=0}^{k-1}\left[p_{e, z}+\left(1-p_{e, z}\right) p_{\text {ack }}\right]\right)+\sum_{k=1}^{Z-1}\left(E_{\text {ack }} \cdot \prod_{z=0}^{k-1}\left[p_{e, z}+\left(1-p_{e, z}\right) p_{\text {ack }}\right]\right)
$$

considerando $p_{e, 0}=1$, correspondente à probabilidade de erro quando nenhuma transmissão é realizada. 
O problema de otimização proposto pode ser definido como

$$
\begin{array}{ll}
\min _{K, n, Z} & E_{\mathrm{ir}}, \\
\text { s.t. } & p_{e}=Q\left(\frac{n C-N+\frac{\log _{2} n}{2}}{\sqrt{n V}}\right) \leq p_{c}^{\frac{1}{K}}, \\
& n_{\mathrm{ca}}=n_{\max }-(Z-1) \cdot n_{\mathrm{ack}}, \\
& 1 \leq n \leq n_{\mathrm{ca}},
\end{array}
$$

em que a busca pelos valores ótimos é realizada a partir da arbitragem de diferentes proporções $\alpha_{z}$, influenciando diretamente em $E_{\text {ir }}$ através de $E_{z}$ e $p_{\mathrm{e}, \mathrm{z}}$. Vale notar que, sendo $n$ o número de usos de canal utilizados até o z-ésimo envio, este pode assumir valores até $n_{\text {ca }}$.

Neste caso, a variável $Z$ é incorporada ao problema de otimização utilizado por Tong et al. (2018) e Silva et al. (2020). Desta forma, além de um comprimento de comandos de controle preditivos $K$, também é encontrado um valor ótimo para o número máximo de transmissões. Esta formulação é equivalente à empregada em (TONG et al., 2018), adotando-se $Z=1$, e (SILVA et al., 2020), para $Z=2$.

Em (TONG et al., 2018), para um caso sem HARQ, foram obtidas as equações para os valores ótimos de potência de transmissão e comprimento do bloco, $P^{\star}$ e $n^{\star}$, respectivamente, sendo

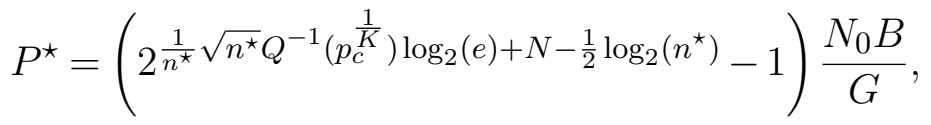

$$
\begin{aligned}
& n^{\star}=n_{\max } .
\end{aligned}
$$

Como estratégia para redução do consumo energético, a utilização de HARQ por Silva et al. (2020), com uma única retransmissão, resultou em uma melhora de até 45\%, e, conforme será apresentado no Capítulo 4, é possível obter valores ainda mais satisfatórios através do uso de um número maior de retransmissões. 


\section{RESULTADOS NUMÉRICOS}

Neste capítulo, o problema de otimização apresentado no Capítulo 3 é validado numericamente por meio de simulação. Os resultados ao se empregar o método proposto são analisados em relação aos de Tong et al. (2018) e Silva et al. (2020). Foram considerados os mesmos valores para os parâmetros, conforme apresentado na Tabela 1, para uma melhor comparação e avaliação dos ganhos.

Tabela 1 - Parâmetros da simulação conforme proposto por Tong et al. (2018) e Silva et al. (2020)

\begin{tabular}{c|c}
\hline \hline Parâmetros & Valores \\
\hline Densidade espectral de potência do AWGN & $N_{0}=-204 \mathrm{dBW} / \mathrm{Hz}$ \\
\hline Ganho do canal & $G=-80 \mathrm{~dB}$ \\
\hline Comprimento do cabeçalho & $H=32 \mathrm{bits}$ \\
\hline Comprimento de cada comando de controle & $L=8 \mathrm{bits}$ \\
\hline Símbolos da mensagem ACK/NACK & $n_{\text {ack }}=10$ \\
\hline Probabilidade de outage de controle & $p_{c}=10^{-9}$ \\
\hline Probabilidade de erro do pacote ACK/NACK & $p_{e, \text { ack }}=10^{-2}$ \\
\hline \hline
\end{tabular}

O equacionamento de pacotes curtos perde precisão para valores de $n<100$, como é o caso da mensagem ACK com $n_{\text {ack }}=10$ (DURISI et al., 2016), (POLYANSKIY et al., 2010). Desta forma, sendo esta composta por apenas um bit de informação, resultando em uma taxa de dados muito baixa, optou-se por utilizar um valor conservador $p_{e, \text { ack }}=10^{-2}$ no lugar do cálculo empregando (10), pois o enlace pode ser considerado naturalmente robusto.

O valor atribuído para $P_{\text {ack }}$ foi de $P_{\text {ir }}$ quando $K=1$. Para as proporções, na primeira transmissão foi estabelecido um valor mínimo de $\alpha_{1}=100 / n_{\text {max }}$ para garantir um mínimo de 100 usos do canal desde a primeira tentativa, e assim obter uma boa precisão nos cálculos. O problema de otimização foi testado para um número de transmissões $Z$ variando entre 2 e 7, pois acima disso, como será apresentado na Seção 4.2, o consumo energético é aumentado, podendo-se então reduzir o escopo da simulação. O número de comandos de controle $K$ foi avaliado de 1 a 10, assim como feito em (SILVA et al., 2020), para facilitar a comparação, mesmo que os resultados deste mesmo trabalho já sugerissem que valores de $K$ mais elevados não seriam benéficos em termos de eficiência energética. 
Os cenários considerados foram $n_{\max }=250,350$ e 500 usos de canal, para os quais os resultados serão apresentados na Seção 4.1, sendo que um maior valor de $n$, conforme descrito no Capítulo 3, representa um requisito de latência $T$ mais relaxado, ou seja, o sistema de controle tolera maiores atrasos.

\subsection{COMPRIMENTO DO COMANDO DE CONTROLE PREDITIVO}

Para encontrar um valor ótimo para o comprimento do comando de controle preditivo, a simulação testou diferentes valores de $K$ para cada número máximo de transmissões $Z$ e calculou a energia total consumida $E_{\text {ir }}$. Para isso, o valor da componente energética correspondente a cada tentativa de envio $E_{z}$, bem como as probabilidades de sucesso ou falha na transmissão da mensagem de controle e do ACK também foram calculadas.

A cada tentativa de envio $z$, foi empregada uma porção do número total de usos de canal disponíveis $n_{\mathrm{z}}$. A gama de porções de usos de canal a ser avaliada para cada transmissão foi pré-definida, sendo também uma variável de entrada da simulação. Foi realizada uma varredura das combinações possíveis de $\alpha_{\mathrm{z}}$, selecionando sempre a menor energia total resultante possível.

A Figura 4 exibe o consumo do recurso sem fio em relação a $K$, para os diferentes valores de $Z$, com $n_{\max }=250$. Pode-se observar que o comprimento do comando de controle preditivo ótimo não é influenciado pela quantidade de retransmissões realizadas, sendo $K=2$.

O mesmo ocorre quando $n_{\max }=350$ para os casos acima de uma retransmissão, conforme representado na Figura 5. Nesta condição, quando $Z=2$, o PPC não agrega vantagens na redução do consumo quando comparado ao HARQ isoladamente. Nas demais situações, pode-se observar que o valor ótimo também é $K=2$.

$\mathrm{Na}$ Figura 6, o mesmo gráfico de energia em função do comprimento de controle preditivo é apresentado para $n_{\max }=500$. É possível notar que o valor ótimo é sempre $K=1$, o que significa que o PPC não é uma estratégia interessante para se acrescentar ao HARQ com o objetivo de minimizar o consumo de recursos da transmissão neste caso. 
Figura 4 - Consumo em função de $K$ para diferentes valores de $Z$, demonstrando a existência de um ponto ótimo para o comprimento de controle preditivo e a redução no gasto energético com o aumento de $Z$

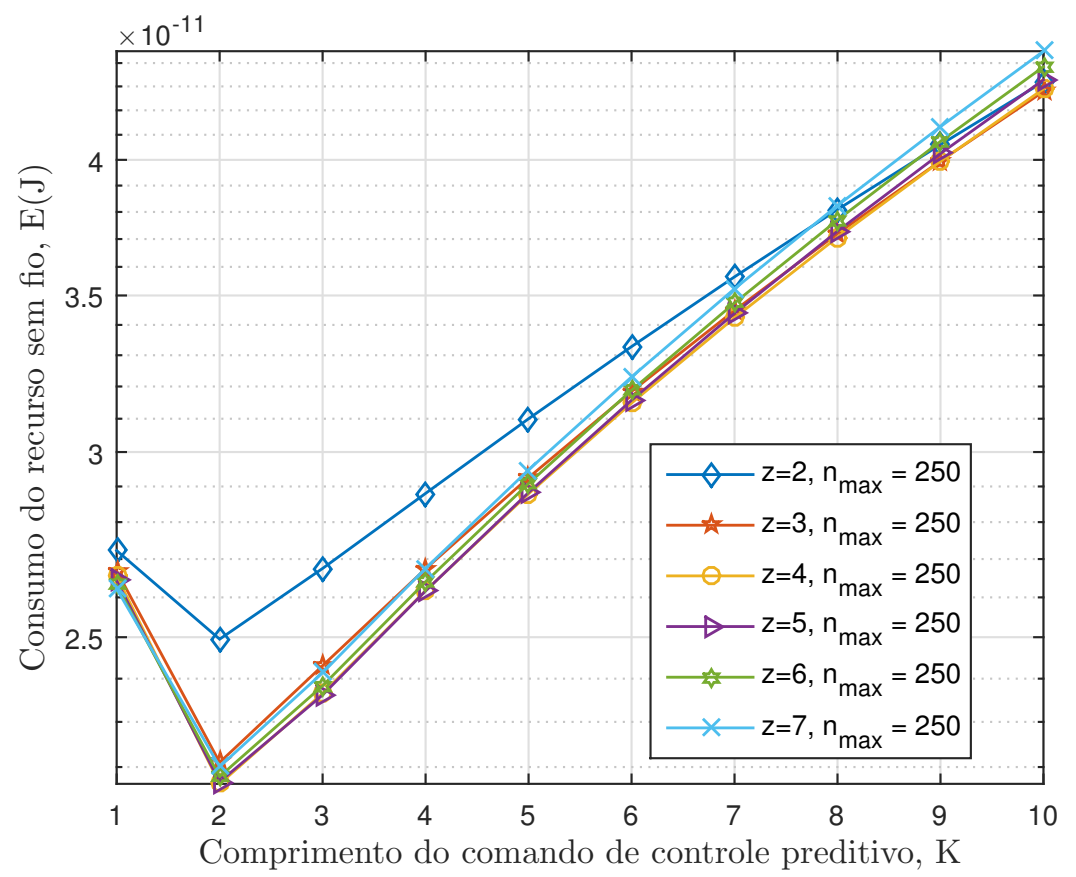

Fonte: Autoria própria.

Figura 5 - Consumo em função de $K$ para diferentes valores de $Z$, demonstrando a existência de um ponto ótimo para o comprimento de controle preditivo e a redução no gasto energético com o aumento de $Z$

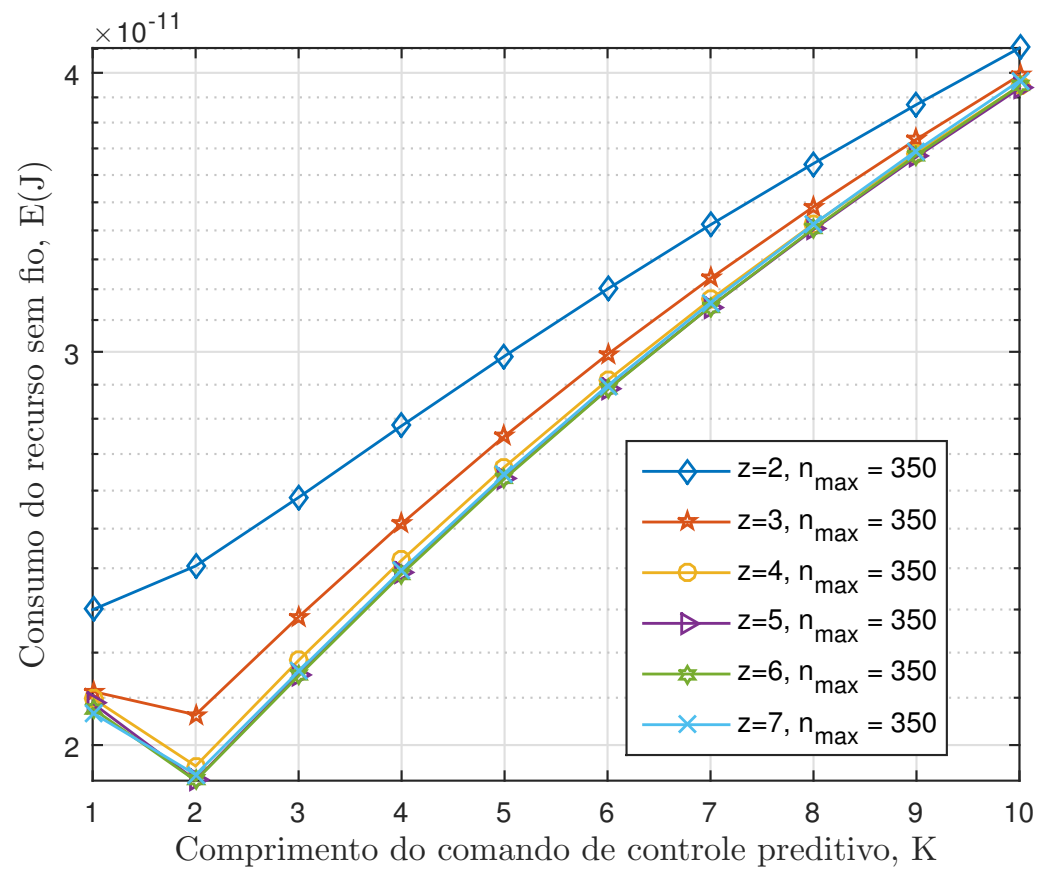

Fonte: Autoria própria. 
Figura 6 - Consumo em função de $K$ para diferentes valores de $Z$, demonstrando que o menor consumo ocorre em $K=1$ e a redução no gasto energético com o aumento de $Z$

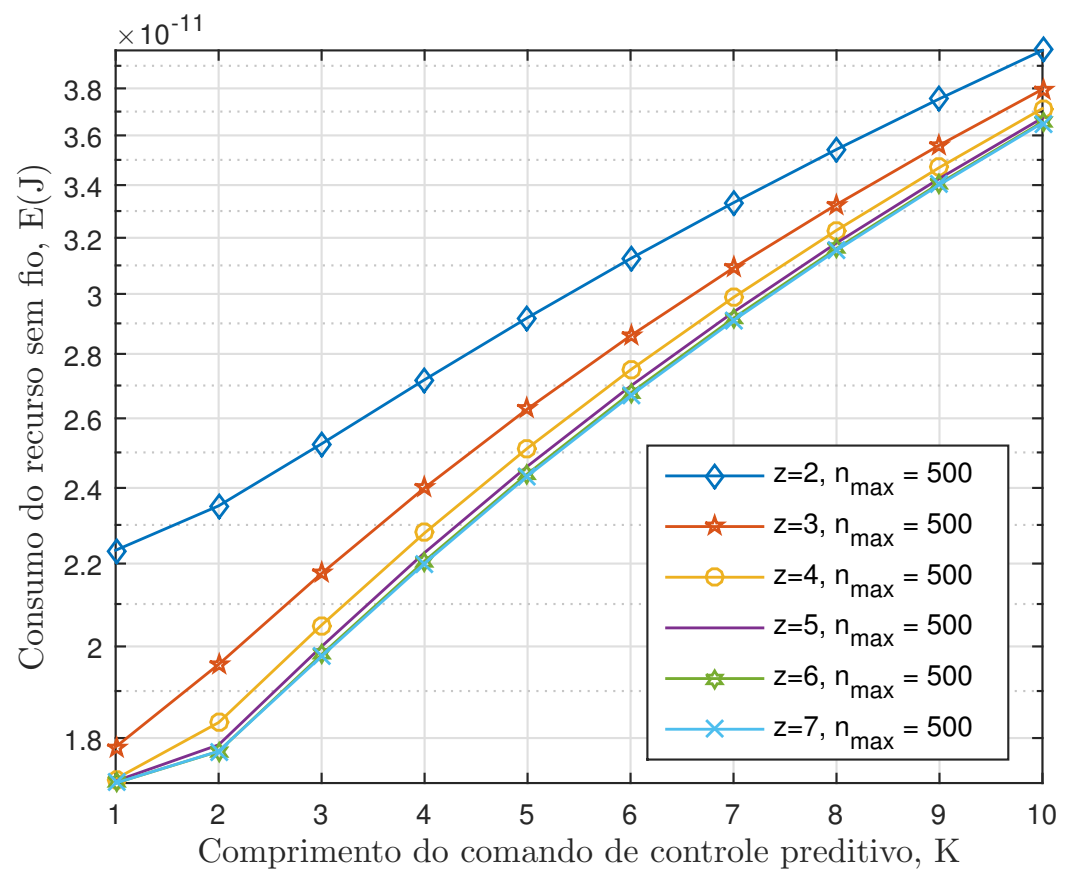

Fonte: Autoria própria.

Na análise apresentada por Tong et al. (2018), em que todos os usos de canal são empregados em um só envio, o comportamento do consumo em relação ao comprimento de controle preditivo $K$ foi associado ao da capacidade do canal $C$, obtida por uma aproximação de (5) ao isolar $C$, chegando a dois termos, em que um ou o outro se torna dominante dependendo dos valores de $n$ e $K$. Quando se aplica o HARQ, o consumo $E_{\text {ir }}$ é muito influenciado pelas componentes energéticas de cada envio $z$. Ainda, a depender do número máximo de transmissões, uma parte da equação representa o impacto do consumo das mensagens ACK/NACK, sendo

$$
E_{\mathrm{ir}}(Z)=\underbrace{\sum_{k=1}^{Z}\left(E_{k} \cdot \prod_{z=0}^{k-1}\left[p_{e, z}+\left(1-p_{e, z}\right) p_{\mathrm{ack}}\right]\right)}_{\text {Consumo componentes } E_{z}}+\underbrace{\sum_{k=1}^{Z-1}\left(E_{\mathrm{ack}} \cdot \prod_{z=0}^{k-1}\left[p_{e, z}+\left(1-p_{e, z}\right) p_{\mathrm{ack}}\right]\right)}_{\text {Consumo mensagens ACK }} .
$$

A energia empregada na primeira transmissão $E_{1}$, sendo a única que não é ponderada por nenhuma probabilidade, tende a exercer um grande impacto sobre o consumo total. A fim de quantificar a contribuição desta componente, a relação $E_{1} / E_{\text {ir }}$ para cada um dos casos avaliados é apresentada nas Figuras 7, 8 e 9, em que pode-se perceber que, no geral, a contribuição fica em torno de $80 \%$. Ainda, vale mencionar que 
o segundo termo, ligado ao consumo das mensagens ACK, é de ordem 10 vezes menor que o primeiro. Com isso, é possível focar na componente $E_{1}$, que possui o maior peso no consumo total, para justificar os efeitos percebidos ao se variar $K$.

Figura 7 - Contribuição de $E_{1}$ para o total $E_{\text {ir }}$ quando $n_{\max }=250$

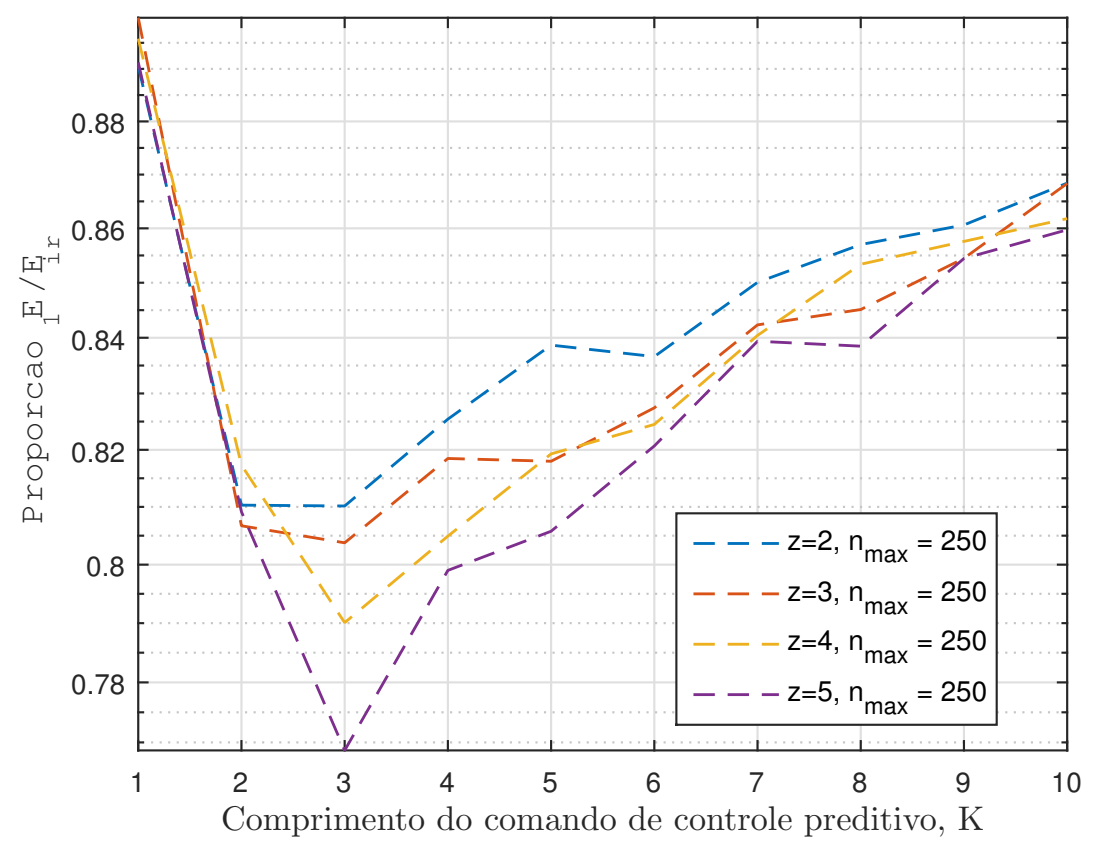

Fonte: Autoria própria.

Conforme apresentado em (14), $E_{z}$ depende tanto da potência de transmissão $P_{\text {ir }}$, quanto do número de usos de canal $n_{\mathrm{z}}$, que, por sua vez, é definido pelos coeficientes $\alpha_{z}$. Para um mesmo $Z$, a potência varia em função de $K$, que, ao ser aumentado, permite um maior valor para $p_{e}$, demandando uma potência menor. Sendo assim, para que seja favorável à diminuição de $E_{1}$, um aumento no valor de $\alpha_{1}$ buscando melhorar o consumo total para um maior comprimento de comando de controle preditivo não pode superar a redução na potência de transmissão provocada por este, do contrário, ele não compensa. Nos casos em que o PPC não foi uma estratégia interessante, as proporções $\alpha_{1}$ que culminaram no melhor consumo para os comprimentos $K>1$ foram superiores à redução em $P_{\text {ir }}$.

No entanto, vale ressaltar que, mesmo nos casos em que a utilização do PPC não é vantajosa, ao se aumentar o número de transmissões utilizado no HARQ para mais que uma retransmissão, o valor do consumo de energia foi melhorado de forma significativa, como será detalhado na Seção 4.2. 
Figura 8 - Contribuição de $E_{1}$ para o total $E_{\text {ir }}$ quando $n_{\max }=350$

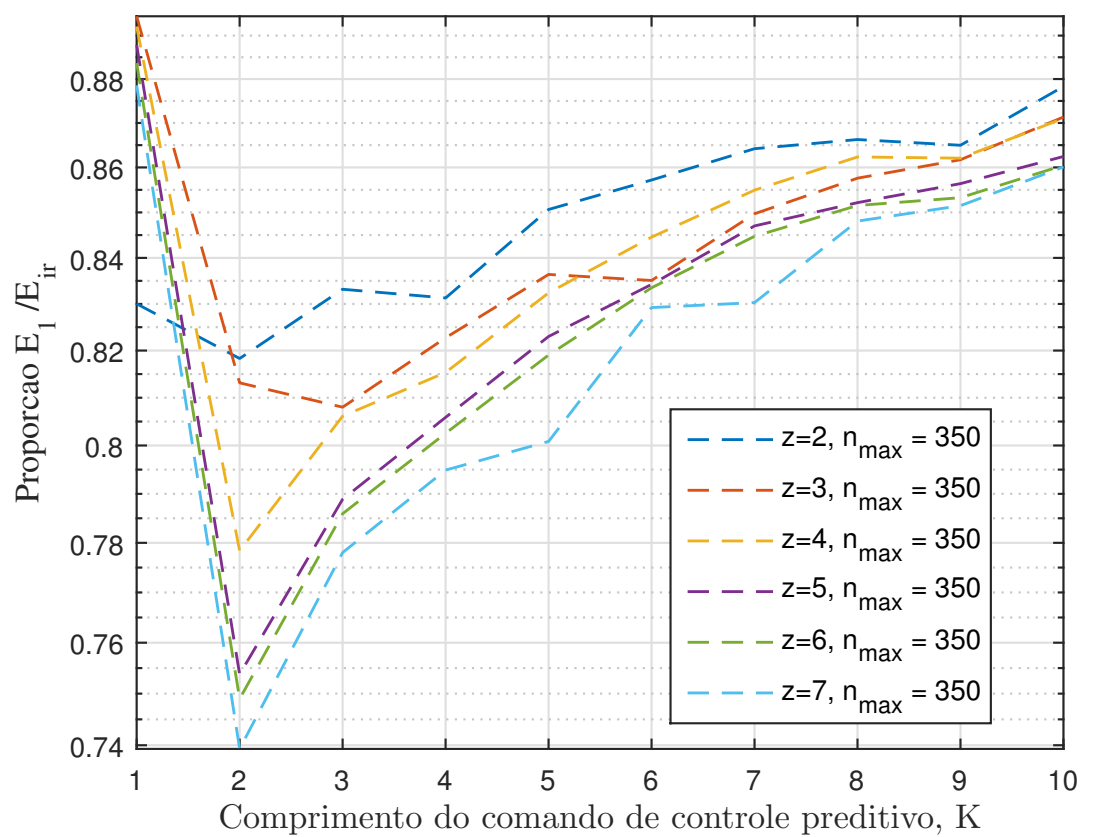

Fonte: Autoria própria.

Figura 9 - Contribuição de $E_{1}$ para o total $E_{\text {ir }}$ quando $n_{\max }=500$

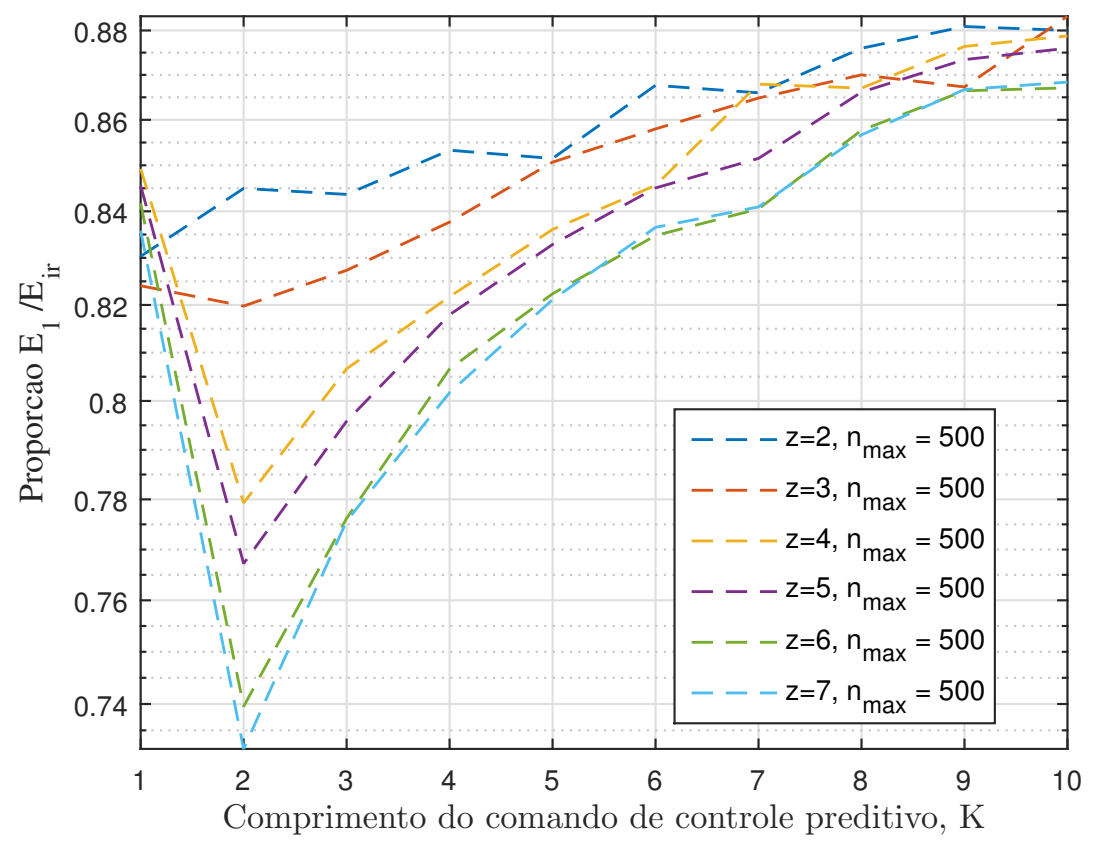

Fonte: Autoria própria. 


\subsection{NÚMERO ÓTIMO DE TRANSMISSÕES}

Conforme mencionado anteriormente, uma consideração importante é a diferença no consumo energético, pois, mesmo nos casos em que o PPC não foi uma estratégia interessante para minimizar o consumo, foi sempre possível economizar recursos mantendo-se a probabilidade de outage de controle com a utilização do HARQ.

Para melhor ilustrar esta análise, a Figura 10 exibe um gráfico do consumo $E_{\text {ir }}$ em relação a $Z$. Para $n_{\max }=250$, e com o comprimento de comandos de controle ótimo $K=2$, o valor do número máximo de transmissões ótimo é $Z=4$. Neste caso, a economia chega a $13,3 \%$ quando se aumenta de $Z=2$ para $Z=4$, demonstrando que de fato a estratégia utilizada por Silva et al. (2020) pode ser aprimorada através do uso de um número maior de retransmissões, proporcionando um menor gasto energético, não só no ponto ótimo, mas para todos os comprimentos de controle avaliados. Se comparada à proposta de Tong et al. (2018), essa economia é ainda mais expressiva, alcançando 52,2\%.

Figura 10 - Consumo em função de $Z$, para $K=2$, com $n_{\max }=250$, apresentando o número máximo de transmissões ótimo, $Z=4$

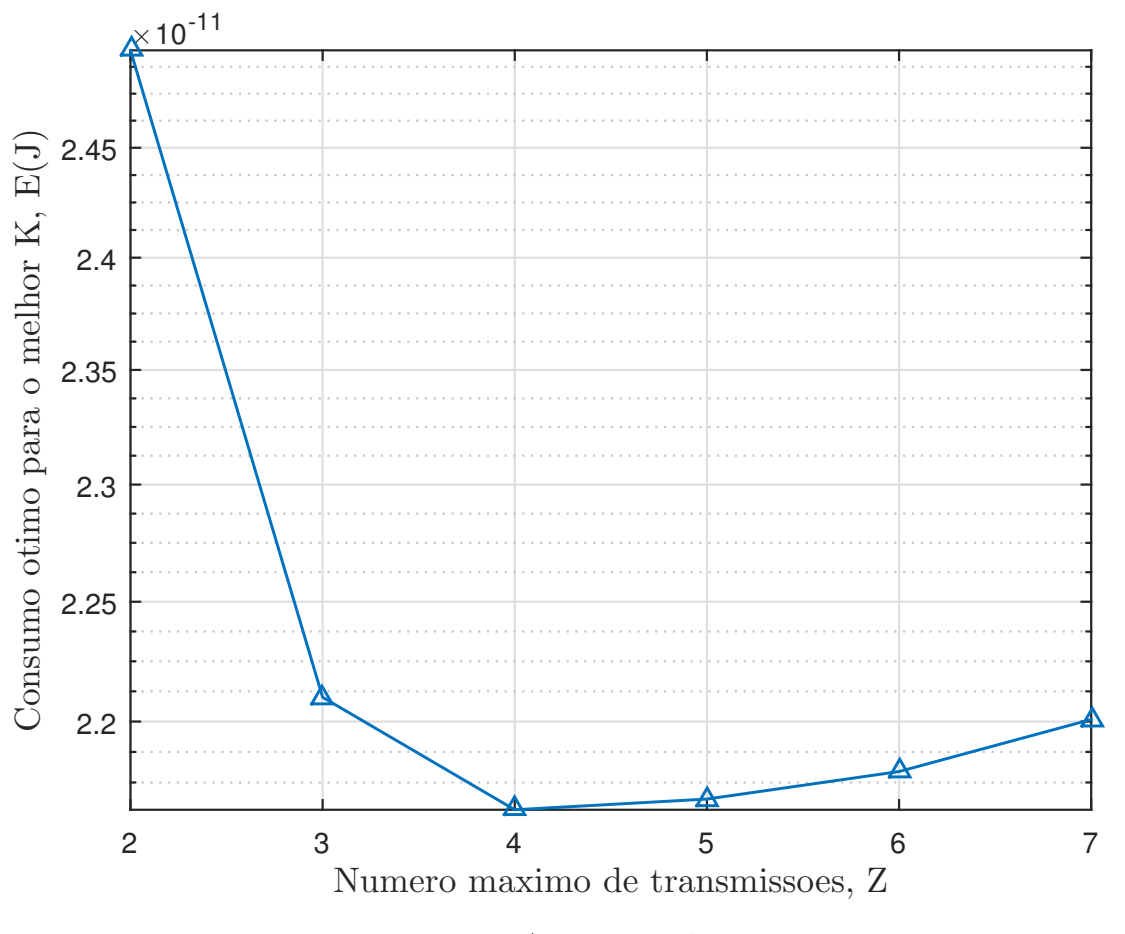

Fonte: Autoria própria.

A Figura 11 apresenta o gráfico do consumo em relação a $Z$ quando $n_{\max }=350$, para os seus respectivos comprimentos ótimos. Lembrando que para $Z=2$, o comprimento ótimo é $K=1$, enquanto que para os demais valores de $Z$ é $K=2$. Nele pode-se observar 
que o ponto de menor consumo ocorre para o número máximo de transmissões $Z=6$, sendo esse o valor ótimo.

Já para o caso de $n_{\max }=500$ apresentado na Figura 12 , em que o PPC não é considerado, sendo o valor do comprimento ótimo sempre $K=1$, o valor do consumo também reduz conforme se aumenta o número máximo de transmissões até $Z=6$, similarmente ao caso anterior. Logo, considerando $n_{\max }=500$, ocorre uma diminuição de 23,5\% quando considera-se o número de transmissões ótimo no lugar de apenas uma retransmissão, como proposto por Silva et al. (2020).

Figura 11 - Consumo em função de $Z$, para os seus respectivos $K$ ótimos, com $n_{\max }=350$, apresentando o número máximo de transmissões ótimo, $Z=6$

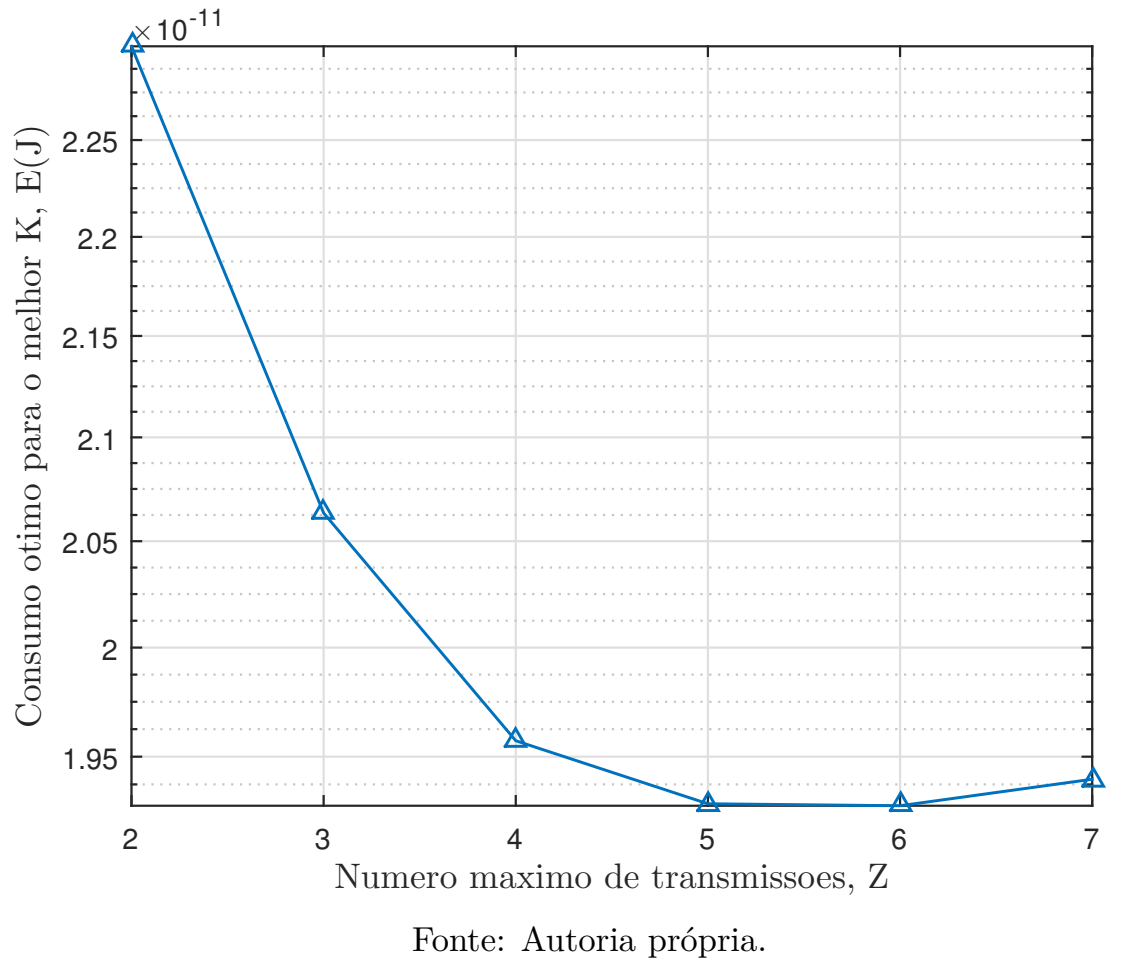

Com o HARQ, a cada tentativa o sistema tem a oportunidade de poupar energia ao evitar as transmissões subsequentes. Por exemplo, após o primeiro envio, existe uma probabilidade de $\left(1-p_{e, 1}\right) \cdot\left(1-p_{\text {ack }}\right)$, que representam uma detecção correta da mensagem e do ACK, respectivamente, de poupar energia. Logo, a escolha da proporção empregada a cada tentativa deve ser feita de forma estratégica, não sendo nem tão baixa que provoque uma perda de pacote elevada, demandando as transmissões subsequentes, reduzindo a probabilidade de poupar energia, nem tão alta que prejudique o consumo ao utilizar uma parcela muito grande de $n_{\text {ca }}$.

É possível observar que conforme o valor de $n_{\max }$ aumenta, maior o valor do 
número máximo de transmissões que promove a melhor eficiência energética. Além das razões já citadas, que influenciam no consumo, quando a restrição de latência é relaxada e o número de usos de canal disponíveis aumenta, a quantidade de símbolos consumidos no envio dos ACK/NACK se torna menos relevante, incrementando os benefícios de um maior $Z$. Além disso, é possível distribuir melhor os usos de canal entre as transmissões, principalmente nos primeiros envios, lembrando que eles têm um peso elevado no consumo total. Este tópico será abordado em mais detalhes na Seção 4.3.

Figura 12 - Consumo em função de $Z$, para $K=1$, com $n_{\max }=500$, apresentando o número máximo de transmissões ótimo, $Z=6$

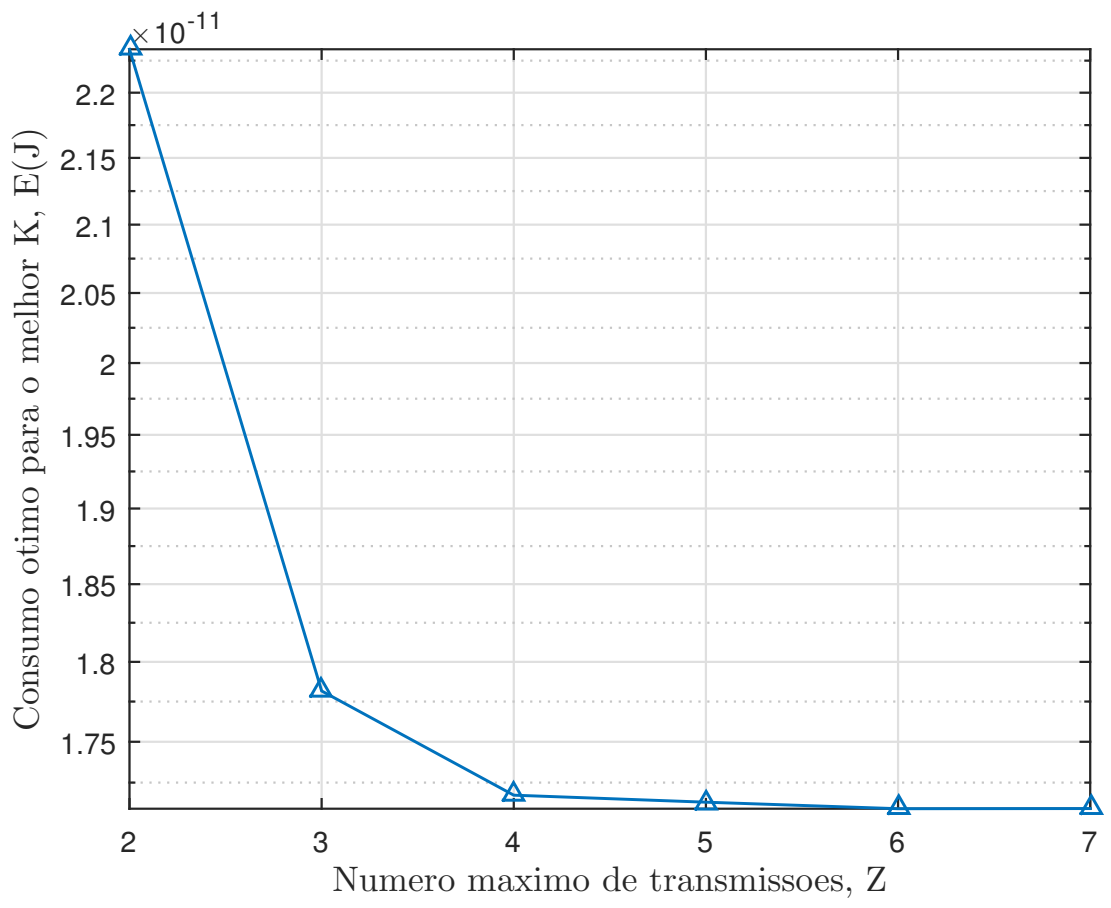

Fonte: Autoria própria.

\subsection{AVALIAÇÃO DO NÚMERO DE USOS DE CANAL}

Outro elemento analisado através da simulação foi a porção de usos de canal empregada em cada um dos casos. Na Figura 13, cada barra corresponde ao coeficiente $\alpha_{\mathrm{z}}$ empregado em cada tentativa de transmissão $z \in\{1, \cdots, Z-1\}$. Esta evidencia que a estratégia adotada consiste em utilizar menos da metade de $n_{\text {ca }}$ na primeira transmissão e poupar o restante, independentemente de $Z$. Além disso, o aumento de diversidade proporcionado por um $Z$ mais elevado faz com que a outage possa ser controlada com um número menor de usos de canal. Observa-se ainda que as retransmissões subsequentes utilizam uma quantidade reduzida de usos de canal, apenas para complementar o envio inicial. No exemplo de quando $n_{\max }=250$, em torno de $6 \%$ de $n_{\text {ca }}$. 
O gráfico para $n_{\max }=350$, exibido na Figura 14, apresenta um comportamento diferente ao descrito anteriormente. Isso se deve ao fato da proporção utilizada quando $Z=2$ ter sido obtida para um $K=1$, enquanto nas demais empregou-se $K=2$, motivo pela qual são discrepantes. Observando-se apenas as barras em que $K=2$, as conclusões obtidas ao se analisar a Figura 13 continuam válidas, no entanto, agora empregando menos de $35 \%$ do $n_{\text {ca }}$ na primeira tentativa de envio, e as demais proporções relativas às transmissões seguintes somam uma proporção de 10\%. É notável também que o número de usos de canal, exceto o último envio que utiliza todos os símbolos remanescentes, se mantém quase constante em aproximadamente $41 \%$.

Figura 13 - Proporção $\alpha_{\mathrm{z}}$ aplicada sobre $n_{\text {ca }}$ a cada transmissão $Z$ de 1 a $Z-1$, para o comprimento ótimo de comandos de controle preditivo para $n_{\max }=250$

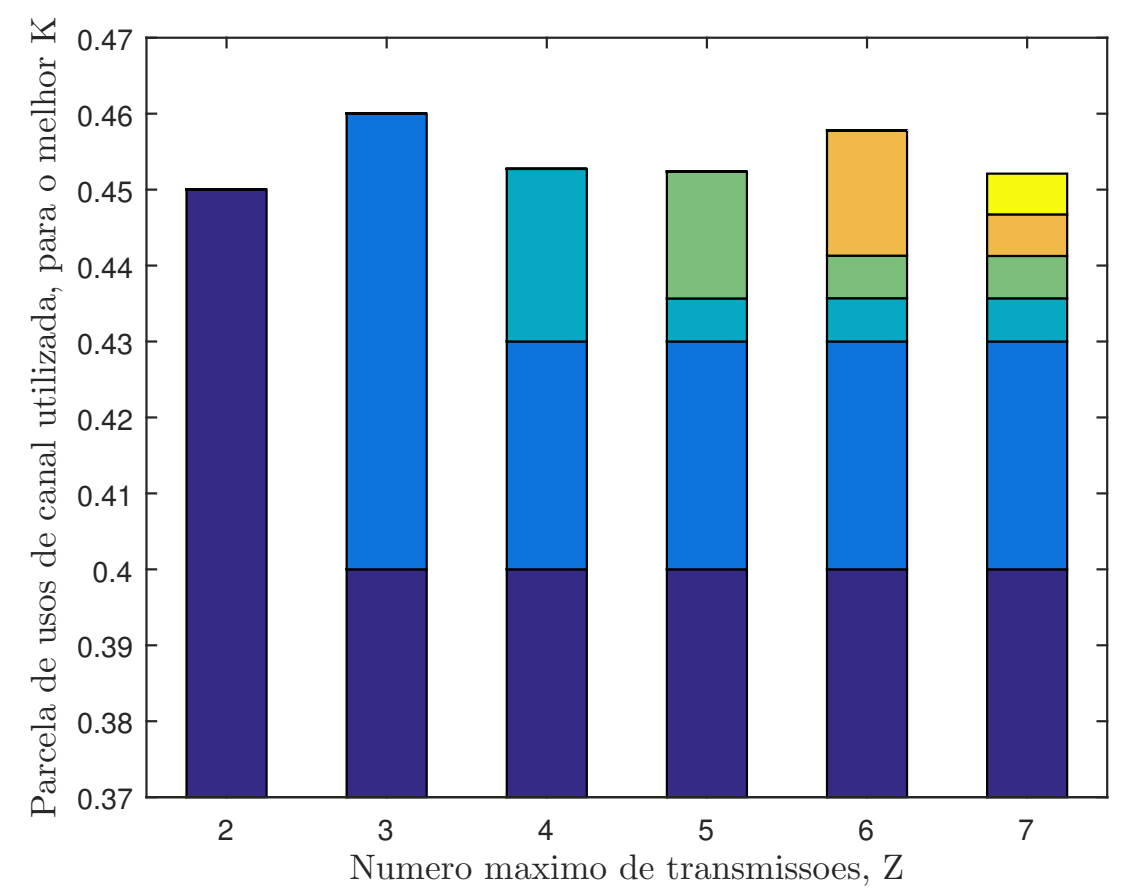

Fonte: Autoria própria.

A Figura 15 mostra as proporções $\alpha_{z}$ quando $n_{\max }=500$. Neste caso, um máximo de apenas $25 \%$ do total de $n_{\text {ca }}$ é empregado nos primeiros envios e, similarmente às análises anteriores, devido à diversidade adicionada pelo HARQ, cerca de $5 \%$ em média é reservado para as demais tentativas. Todo o restante fica então disponível para a situação em que a última tentativa de transmissão seja necessária.

Na Seção 4.1 foi mencionado o impacto de um aumento no valor de $\alpha_{1}$ superior

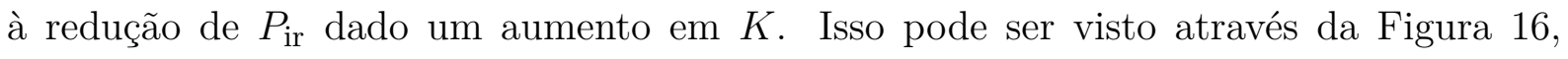
comparando as proporções para $K=1$ e $K=2$, sendo $n_{\max }=350$. Nesta situação, 
Figura 14 - Proporção $\alpha_{\mathrm{z}}$ aplicada sobre $n_{\text {ca }}$ a cada transmissão $Z$ de 1 a $Z-1$, para o comprimento ótimo de comandos de controle preditivo para $n_{\max }=350$

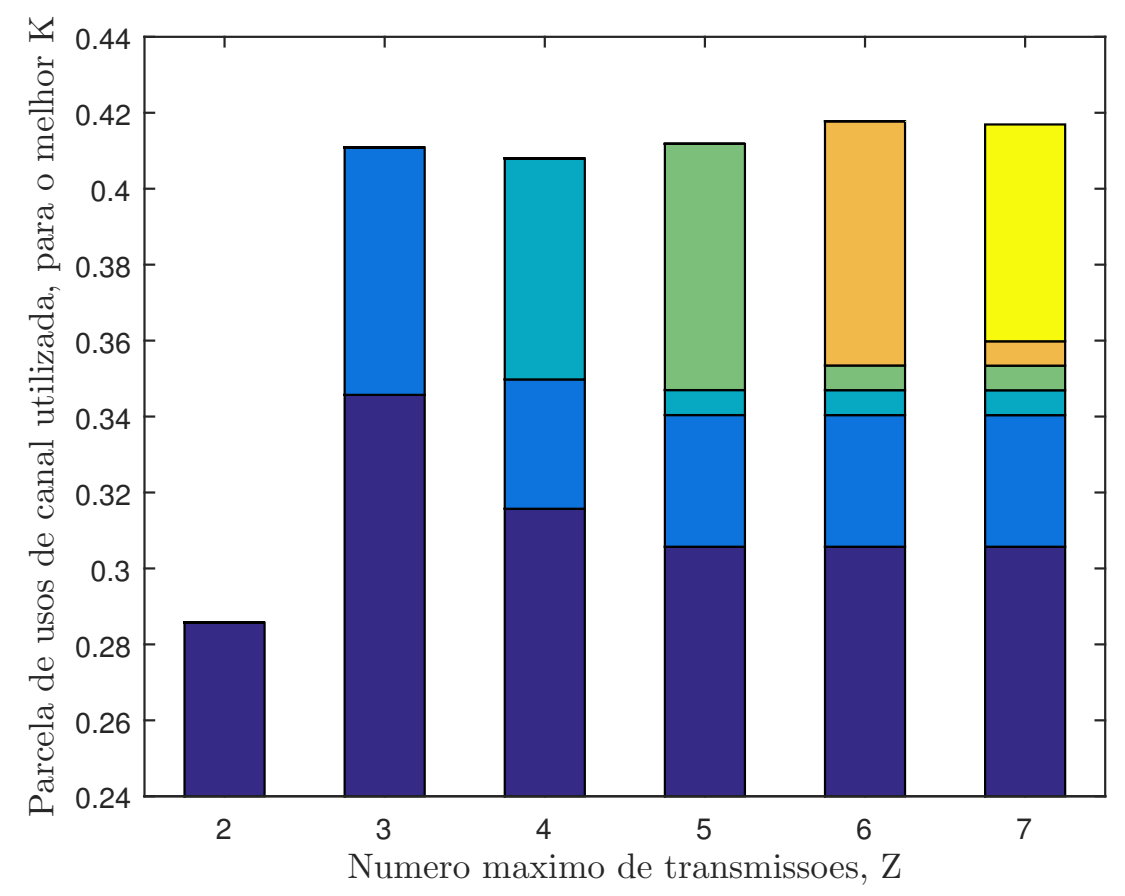

Fonte: Autoria própria.

Figura 15 - Proporção $\alpha_{\mathrm{z}}$ aplicada sobre $n_{\text {ca }}$ a cada transmissão $Z$ de 1 a $Z-1$, para o comprimento ótimo de comandos de controle preditivo para $n_{\max }=500$

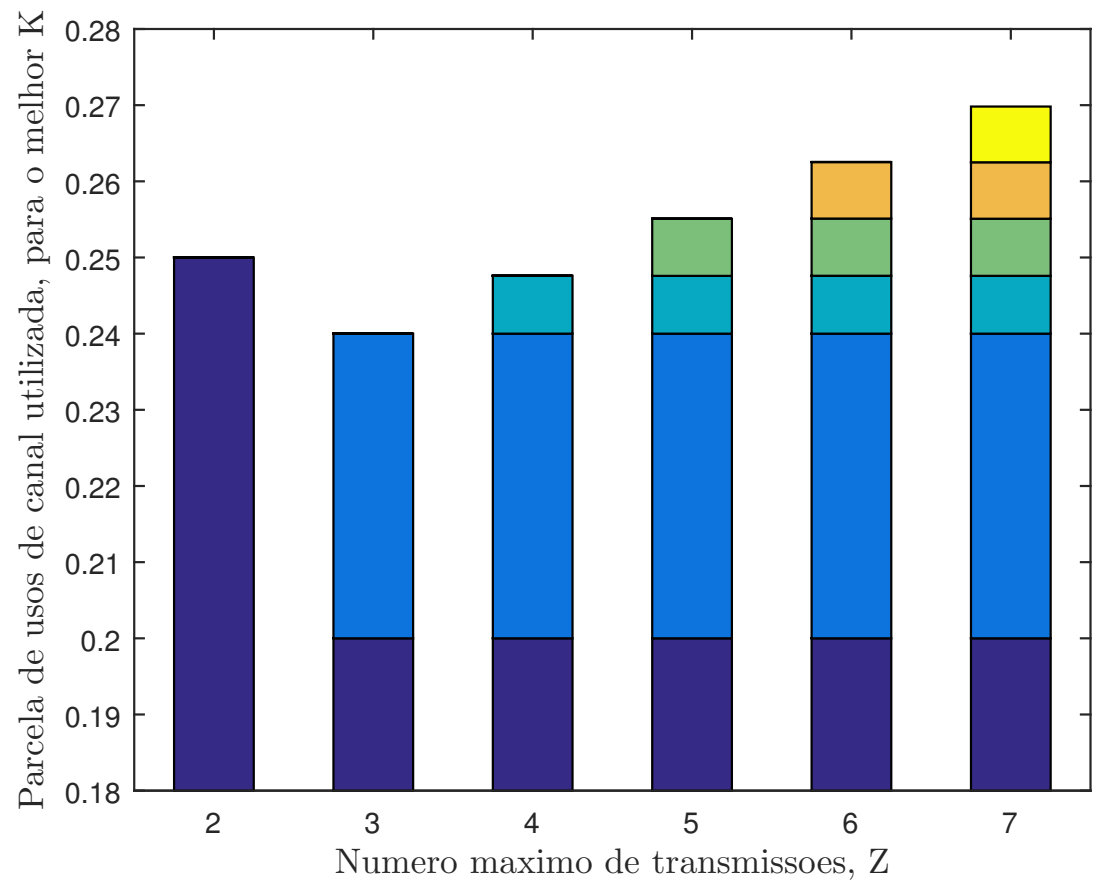

Fonte: Autoria própria. 
quando $Z=2$, o valor de $\alpha_{1}$ sofre um aumento de $42 \%$, o que supera a redução em $P_{\text {ir }}$, que fica em $26 \%$, fazendo com que o comprimento de controle preditivo ótimo seja 1 . Já quando $Z=3$, a diferença entre os valores de $\alpha_{1}$ é de $21 \%$, e $10 \%$ para $Z=4$, tornando o PPC uma estratégia interessante nestes casos.

Figura 16 - Proporção $\alpha_{\mathrm{z}}$ aplicada sobre $n_{\text {ca }}$ a cada transmissão $Z$ de 1 a $Z-1$, para os comprimentos de comandos de controle preditivo $K=1$ e $K=2$, para $n_{\max }=350$
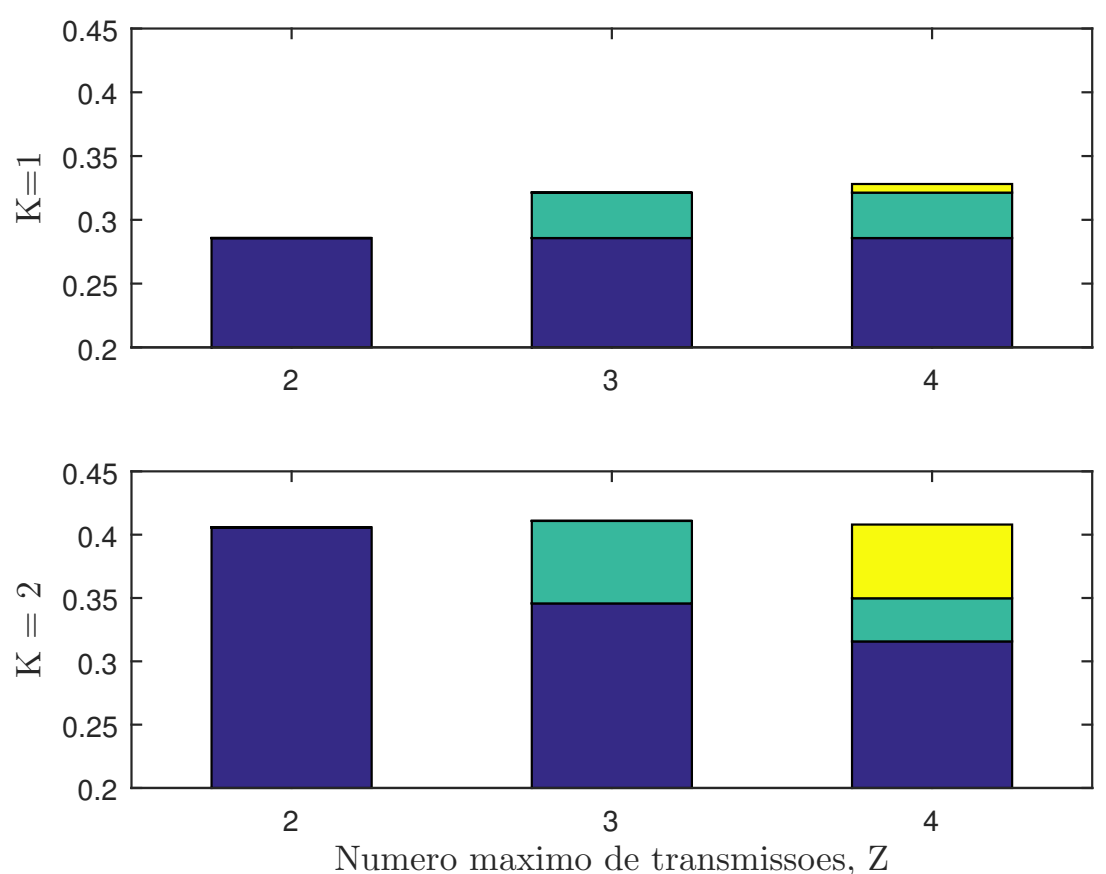

Fonte: Autoria própria. 


\section{CONCLUSÕES E TRABALHOS FUTUROS}

Neste trabalho foi proposto um método de alocação de recursos que otimiza o gasto energético em sistemas de controle via redes sem fio, baseado em controle preditivo em pacotes e HARQ de redundância incremental. Entre as suas contribuições, estendendo o trabalho proposto por Silva et al. (2020), foi encontrado o equacionamento da energia total consumida na transmissão $E_{\text {ir }}$, objeto da busca pelo menor consumo no problema de otimização em questão.

Foram avaliados três cenários, com diferentes valores para o número máximo de usos de canal. No primeiro, sendo $n_{\max }=250$, encontrou-se uma quantidade ótima de comandos de controle $K=2$ para as condições estipuladas, independentemente da quantidade de transmissões, e um valor ótimo de $Z=4$ transmissões ao máximo, em que se encontra o melhor consumo. Isso se traduz em uma redução de 13,3\%, quando comparando a HARQ com uma única retransmissão (SILVA et al., 2020), e uma economia de 52,2\% em relação ao caso em que não foi aplicado HARQ (TONG et al., 2018).

No segundo cenário, para $n_{\max }=350$, o melhor consumo ocorreu para $K=2$ quando $Z=6$. Uma conclusão interessante para este caso foi de que, seguindo o esquema proposto por Silva et al. (2020), em que $Z=2$, o valor ótimo do comprimento de comando preditivo foi $K=1$, o que significa que, quando comparado ao se utilizar unicamente o HARQ, o PPC não contribuiu para a redução do consumo nesta situação. Já com um número maior de retransmissões, a utilização do PPC voltou a ser favorável à eficiência energética, especialmente pela possibilidade de distribuir melhor o número de usos de canal, enfatizando a importância e a vantagem de serem avaliados diferentes valores para o número máximo de transmissões.

Conforme já observado por Silva et al. (2020) para $n_{\max }=500$ e $Z=2$, o valor do comprimento ótimo também foi $K=1$ para todos os demais valores de $Z$ simulados, ou seja, o PPC não foi uma estratégia interessante para minimizar o gasto energético nesta condição. Mesmo assim, ao se empregar HARQ com um maior número de retransmissões, foi possível obter como resultado uma diminuição de 23,5\% no consumo energético ao ser considerado o número ótimo de transmissões $Z=6$ no lugar de apenas uma retransmissão.

Além disso, os resultados das simulações mostraram que a estratégia adotada utiliza menos da metade dos usos de canal disponíveis na primeira tentativa de envio, sendo essa proporção ainda menor para maiores valores de número máximo de usos de 
canal, chegando a $25 \%$ para $n_{\max }=500$. As retransmissões subsequentes utilizam uma quantidade reduzida de usos de canal, apenas para complementar o envio inicial, em torno de 5 a $10 \%$ de $n_{\text {ca. }}$. O restante é empregado somente na situação em que a última tentativa de envio se faz necessária, com seu consumo atrelado à probabilidade desta ocorrência, possibilitando então reduzir o consumo da transmissão.

Desta forma, com a possibilidade de controlar a outage com um número menor de usos de canal devido ao aumento de diversidade proporcionado por um $Z$ mais elevado, é possível realizar uma comunicação com os mesmos requisitos e com um consumo reduzido, o que valida os ganhos da metodologia proposta.

Em relação aos trabalhos futuros, uma evolução possível deste estudo seria a avaliação dos resultados ao se modificarem os parâmetros da simulação, como por exemplo, a probabilidade de outage de controle permitida, que neste trabalho foi de $p_{c}=10^{-9}$.

Outra possível extensão seria comparar o uso de PPC combinado com HARQ de tipo II analisado, com a abordagem de se empregar uma otimização por alocação de potência conforme Dosti et al. (2017) propôs para HARQ de tipo I, e avaliar se existem ganhos na redução consumo da transmissão.

Neste trabalho foi considerado um canal com forte linha de visada, sendo modelado como um canal AWGN. Poderiam ser avaliados outros tipos de canal.

Ainda, a efetividade de se ter um relé ao invés de serem adotadas retransmissões com o objetivo de redução do consumo pode ser avaliada, uma vez que o método de se empregar o PPC em um sistema com relé e otimização da alocação de potência já foi indicado como uma boa alternativa para minimizar a probabilidade de perda de pacotes por Xie et al. (2019). 


\section{REFERÊNCIAS}

ANDREWS, J. G.; BUZZI, S.; CHOI, W.; HANLY, S. V.; LOZANO, A.; SOONG, A. C. K.; ZHANG, J. C. What will $5 \mathrm{~g}$ be? IEEE Journal on Selected Areas in Communications, v. 32, n. 6, p. 1065-1082, June 2014. ISSN 0733-8716.

BELLO, L. L.; AKERBERG, J.; GIDLUND, M.; UHLEMANN, E. Guest editorial special section on new perspectives on wireless communications in automation: From industrial monitoring and control to cyber-physical systems. IEEE Transactions on Industrial Informatics, Institute of Electrical and Electronics Engineers (IEEE), v. 13, n. 3, p. 1393-1397, jun 2017.

BRAYER, K. Error control techniques using binary symbol burst codes. IEEE Transactions on Communication Technology, v. 16, n. 2, p. 199-214, April 1968. ISSN 0018-9332.

CHEN, H.; ABBAS, R.; CHENG, P.; SHIRVANIMOGHADDAM, M.; HARDJAWANA, W.; BAO, W.; LI, Y.; VUCETIC, B. Ultra-reliable low latency cellular networks: Use cases, challenges and approaches. IEEE Communications Magazine, v. 56, n. 12, p. $119-125,2018$.

CHENG, S.; HORNG, G.; CHOU, C. Using cellular automata to form car society in vehicular ad hoc networks. IEEE Transactions on Intelligent Transportation Systems, v. 12, n. 4, p. 1374-1384, Dec 2011. ISSN 1524-9050.

DOSTI, E.; WIJEWARDHANA, U. L.; ALVES, H.; LATVA-AHO, M. Ultra reliable communication via optimum power allocation for type-i arq in finite block-length. In: 2017 IEEE International Conference on Communications (ICC). 2017. p. 1-6. ISSN 1938-1883.

DURISI, G.; KOCH, T.; POPOVSKI, P. Toward massive, ultrareliable, and low-latency wireless communication with short packets. Proceedings of the IEEE, v. 104, n. 9, p. 1711-1726, Sept 2016. ISSN 0018-9219.

ERICSSON. Cellular networks for Massive IoT. White Paper, January 2020.

European Truck Platooning. ITS Corridors. 2018. Disponível em: $<$ https://www.eutruckplatooning.com/Themes/ITS+Corridors/default.aspx > .

GOLDSMITH, A. Wireless Communications. Cambridge, U.K: Cambridge Univ. Press, 2005.

HARTENSTEIN, H.; LABERTEAUX, L. P. A tutorial survey on vehicular ad hoc networks. IEEE Communications Magazine, v. 46, n. 6, p. 164-171, June 2008. ISSN 0163-6804.

HORIZON2020. ENSEMBLE Project. out. 2020. Disponível em: $<$ https://platooningensemble.eu $>$. 
HOU, Z.; SHE, C.; LI, Y.; ZHUO, L.; VUCETIC, B. Prediction and communication co-design for ultra-reliable and low-latency communications. IEEE Transactions on Wireless Communications, v. 19, n. 2, p. 1196-1209, 2020.

HUANG, J. H.; LEE, M. R.; TSAI, M.; CHIU, S. F. Generalized predictive control in a wireless networked control system. In: 2011 9th World Congress on Intelligent Control and Automation. 2011. p. 870-875.

KIHL, M.; BÜR, K.; MAHANTA, P.; COELINGH, E. 3gpp lte downlink scheduling strategies in vehicle-to-infrastructure communications for traffic safety applications. In: 2012 IEEE Symposium on Computers and Communications (ISCC). 2012. p. 000448-000453. ISSN 1530-1346.

LIN, S.; COSTELlO, D. J.; MILLER, M. J. Automatic-repeat-request error-control schemes. IEEE Communications Magazine, v. 22, n. 12, p. 5-17, 1984.

Lin Xiao; Johansson, M.; Hindi, H.; Boyd, S.; Goldsmith, A. Joint optimization of communication rates and linear systems. IEEE Transactions on Automatic Control, v. 48 , n. 1 , p. $148-153,2003$.

LU, N.; CHENG, N.; ZHANG, N.; SHEN, X.; MARK, J. W. Connected vehicles: Solutions and challenges. IEEE Internet of Things Journal, v. 1, n. 4, p. 289-299, Aug 2014. ISSN 2327-4662.

NADAS, J. P. B.; IMRAN, M. A.; BRANTE, G.; SOUZA, R. D. Optimizing the energy efficiency of short term ultra reliable communications in vehicular networks. In: 2017 15th International Symposium on Modeling and Optimization in Mobile, Ad Hoc, and Wireless Networks (WiOpt). 2017. p. 1-6.

NADAS, J. P. B.; ONIRETI, O.; SOUZA, R. D.; ALVES, H.; BRANTE, G.; IMRAN, M. A. Performance analysis of hybrid arq for ultra-reliable low latency communications. IEEE Sensors Journal, v. 19, n. 9, p. 3521-3531, 2019.

OSSEIRAN, A.; BOCCARDI, F.; BRAUN, V.; KUSUME, K.; MARSCH, P.; MATERNIA, M.; QUESETH, O.; SCHELLMANN, M.; SCHOTTEN, H.; TAOKA, H.; TUllBerG, H.; UUSITAlO, M. A.; TIMUS, B.; FAllGREN, M. Scenarios for $5 \mathrm{~g}$ mobile and wireless communications: the vision of the metis project. IEEE Communications Magazine, v. 52, n. 5, p. 26-35, 2014.

OZAROW, L. H.; SHAMAI, S.; WYNER, A. D. Information theoretic considerations for cellular mobile radio. IEEE Transactions on Vehicular Technology, v. 43, n. 2, p. 359-378, May 1994. ISSN 0018-9545.

PARK, P.; ERGEN, S. C.; FISCHIONE, C.; LU, C.; JOHANSSON, K. H. Wireless network design for control systems: A survey. IEEE Communications Surveys Tutorials, v. 20, n. 2, p. 978-1013, 2018.

Peloton Technology. Peloton Technology. 2018. Disponível em: <https://pelotontech.com/>.

POLYANSKIY, Y.; POOR, H. V.; VERDU, S. Channel coding rate in the finite blocklength regime. IEEE Transactions on Information Theory, v. 56, n. 5, p. 23072359, May 2010. ISSN 0018-9448. 
POPOVSKI, P. Ultra-reliable communication in $5 \mathrm{~g}$ wireless systems. In: 1st International Conference on 5G for Ubiquitous Connectivity. 2014. p. 146-151.

POPOVSKI, P.; NIELSEN, J. J.; STEFANOVIC, C.; CARVALHO, E. d.; STROM, E.; TRILlingSGAARD, K. F.; BANA, A.; KIM, D. M.; KOTABA, R.; PARK, J.; SORENSEN, R. B. Wireless access for ultra-reliable low-latency communication: Principles and building blocks. IEEE Network, v. 32, n. 2, p. 16-23, 2018.

POPOVSKI, P.; STEFANOVIĆ Č.; NIELSEN, J. J.; CARVALHO, E. de; ANGJELICHINOSKI, M.; TRILLINGSGAARD, K. F.; BANA, A. Wireless access in ultra-reliable low-latency communication (URLLC). IEEE Transactions on Communications, v. 67, n. 8, p. 5783-5801, 2019.

QIN, S.; BADGWELL, T. A. A survey of industrial model predictive control technology. Control Engineering Practice, v. 11, n. 7, p. 733-764, 2003. ISSN 0967-0661. Disponível em: <http://www.sciencedirect.com/science/article/pii/S0967066102001867>.

SADI, Y.; ERGEN, S. C.; PARK, P. Minimum energy data transmission for wireless networked control systems. IEEE Transactions on Wireless Communications, v. 13, n. 4 , p. $2163-2175,2014$.

SARTRE. Autonomous car platoons. 2018. Disponível em: $<$ https://spectrum.ieee.org/automaton/robotics/industrial-robots/sartre-autonomouscar-platoons $>$.

Scaciota, R.; Moritz, G. L.; Brante, G.; Souza, R. D. Minimization of energy consumption per bit using an average dwell-time approach for wireless networked control systems. IEEE Access, v. 7, p. 81839-81848, 2019.

SHAH, S. A. A.; AHMED, E.; IMRAN, M.; ZEADALLY, S. 5g for vehicular communications. IEEE Communications Magazine, v. 56, n. 1, p. 111-117, 2018.

SHANNON, C. E. A mathematical theory of communication. Bell Syst. Tech. J., v. 27, p. 379-423, jul. 1948.

Sharmila, S.; Shanthi, T. A survey on wireless ad hoc network: Issues and implementation. In: 2016 International Conference on Emerging Trends in Engineering, Technology and Science (ICETETS). 2016. p. 1-6.

SILVA, F. E. da; IAREMCZUK, A. L. V.; SOUZA, R. D.; BRANTE, G.; MORITZ, G. L.; HUSSAIN, S. Hybrid arq in wireless packetized predictive control. IEEE Sensors Letters, v. 4, n. 5, p. 1-4, 2020.

SWEDEN4PLATOONING. Closing Conference. jul. 2020. Disponível em: $<$ https://sites.google.com/view/s4pcc/>.

TONG, X.; ZHAO, G.; IMRAN, M. A.; PANG, Z.; CHEN, Z. Minimizing wireless resource consumption for packetized predictive control in real-time cyber physical systems. In: 2018 IEEE International Conference on Communications Workshops (ICC Workshops). 2018. p. 1-6. 
TUlLBERG, H.; POPOVSKI, P.; LI, Z.; UUSITALO, M. A.; HOGLUND, A.; BULAKCI, O.; FALLGREN, M.; MONSERRAT, J. F. The metis $5 \mathrm{~g}$ system concept: Meeting the $5 \mathrm{~g}$ requirements. IEEE Communications Magazine, v. 54, n. 12, p. 132-139, December 2016. ISSN 0163-6804.

ULUSOY, A.; GURBUZ, O.; ONAT, A. Wireless model-based predictive networked control system over cooperative wireless network. IEEE Transactions on Industrial Informatics, v. 7, n. 1, p. 41-51, 2011.

WANG, Q.; XIE, S.; ZHAO, G.; ZHANG, L.; CHEN, Z. Urllc packet management for packetized predictive control. In: 2019 IEEE Wireless Communications and Networking Conference (WCNC). 2019. p. 1-5.

WANG, Q.; ZOU, Y.; NIU, Y. Event-triggered model predictive control for wireless networked control systems with packet losses. In: 2015 IEEE International Conference on Cyber Technology in Automation, Control, and Intelligent Systems (CYBER). 2015. p. 1281-1286.

Xiangheng Liu; Goldsmith, A. Wireless network design for distributed control. In: 2004 43rd IEEE Conference on Decision and Control (CDC) (IEEE Cat. No.04CH37601). 2004. v. 3, p. 2823-2829 Vol.3.

XIE, S.; CHANG, B.; ZHAO, G.; CHEN, Z.; HUANG, Y. Optimal power allocation for relay-assisted wireless packetized predictive control. In: 2019 24th IEEE International Conference on Emerging Technologies and Factory Automation (ETFA). 2019. p. $1143-1147$.

YANG, W.; DURISI, G.; KOCH, T.; POLYANSKIY, Y. Block-fading channels at finite blocklength. In: ISWCS 2013; The Tenth International Symposium on Wireless Communication Systems. 2013. p. 1-4.

ZHANG, B. Energy Optimization for Hybrid ARQ. 2020. Tese (Doutorado) - UC San Diego, 2020.

ZHANG, L.; GAO, H.; KAYNAK, O. Network-induced constraints in networked control systems-a survey. IEEE Transactions on Industrial Informatics, v. 9, n. 1, p. 403416, 2013.

ZHAO, G.; IMRAN, M. A.; PANG, Z.; CHEN, Z.; LI, L. Toward real-time control in future wireless networks: Communication-control co-design. IEEE Communications Magazine, v. 57, n. 2, p. 138-144, 2019.

ZHENG, K.; ZHENG, Q.; CHATZIMISIOS, P.; XIANG, W.; ZHOU, Y. Heterogeneous vehicular networking: A survey on architecture, challenges, and solutions. IEEE Communications Surveys Tutorials, v. 17, n. 4, p. 2377-2396, Fourthquarter 2015. ISSN 1553-877X. 